OPEN ACCESS

Edited by: Spyros Pournaras, National and Kapodistrian University of Athens, Greece

Reviewed by: Vincenzo Di Pilato,

University of Genoa, Italy Bartolome Moya Canellas, Instituto de Investigación Sanitaria de Palma, Spain

*Correspondence: Seok Hoon Jeong kscpjsh@yuhs.ac

Specialty section: This article was submitted to Antimicrobials, Resistance and Chemotherapy,

a section of the journal

Frontiers in Microbiology

Received: 05 October 2020

Accepted: 04 January 2021

Published: 18 February 2021

Citation:

Yoon E-J and Jeong SH (2021) Mobile Carbapenemase Genes

in Pseudomonas aeruginosa.

Front. Microbiol. 12:614058. doi: $10.3389 /$ fmicb.2021.614058

\section{Mobile Carbapenemase Genes in Pseudomonas aeruginosa}

\author{
Eun-Jeong Yoon and Seok Hoon Jeong* \\ Department of Laboratory Medicine and Research Institute of Bacterial Resistance, Yonsei University College of Medicine, \\ Seoul, South Korea
}

Carbapenem-resistant Pseudomonas aeruginosa is one of the major concerns in clinical settings impelling a great challenge to antimicrobial therapy for patients with infections caused by the pathogen. While membrane permeability, together with derepression of the intrinsic beta-lactamase gene, is the global prevailing mechanism of carbapenem resistance in $P$. aeruginosa, the acquired genes for carbapenemases need special attention because horizontal gene transfer through mobile genetic elements, such as integrons, transposons, plasmids, and integrative and conjugative elements, could accelerate the dissemination of the carbapenem-resistant $P$. aeruginosa. This review aimed to illustrate epidemiologically the carbapenem resistance in $P$. aeruginosa, including the resistance rates worldwide and the carbapenemase-encoding genes along with the mobile genetic elements responsible for the horizontal dissemination of the drug resistance determinants. Moreover, the modular mobile elements including the carbapenemase-encoding gene, also known as the $P$. aeruginosa resistance islands, are scrutinized mostly for their structures.

\footnotetext{
Keywords: carbapenem resistance, carbapenemase, molecular epidemiology, Pseudomonas aeruginosa, mobile genetic elements, genomic islands
}

\section{INTRODUCTION}

Pseudomonas aeruginosa is a non-fermentative and aerobic Gram-negative bacillus that is one of the leading causes of severe health care-associated infections targeting immunocompromised patients (Rice, 2008). The bacterial species is an opportunistic pathogen not only for humans but also for plants and animals. $P$. aeruginosa is metabolically versatile, and it has an enormous ability for adaptation to different conditions with genome plasticity (Shen et al., 2006). There are diverse opinions whether the pangenome of $P$. aeruginosa is still open or closed to acquire foreign genes (Klockgether et al., 2011; Mosquera-Rendon et al., 2016). The accessory genome is often composed of genes involved in virulence to human hosts and antimicrobial resistance, resulting in a high risk of mortality and a high rate of multidrug resistance (Moradali et al., 2017). P. aeruginosa has a median genome size value of $6.7 \mathrm{Mbp}$, a median number of 6,016 coding sequences, and $66.1 \% \mathrm{GC}$ on average (NCBI, 2020).

Although beta-lactams are one of the most commonly used antimicrobial drug classes for $P$. aeruginosa infection, antipseudomonal beta-lactam drugs are limited because of the species' intrinsic resistance due to the interplay of chromosomal beta-lactamases (Livermore and Yang, 1987), a low outer membrane permeability (Angus et al., 1982), and the constitutive expression of efflux pump systems (Li et al., 1995). The beta-lactam regimens for $P$. aeruginosa infection include antipseudomonal penicillins in combination with a beta-lactamase 
inhibitor, i.e., piperacillin-tazobactam and ticarcillin-clavulanic acid; antipseudomonal cephalosporins alone or in combination with beta-lactamase inhibitors, i.e., ceftazidime (with avibactam), ceftolozane (with tazobactam), cefoperazone (with sulbactam), and cefepime (Slack, 1981); and carbapenems, i.e., imipenem and meropenem. Among those, carbapenems are the preferred choice against multidrug-resistant $P$. aeruginosa. In recent years, the rate of carbapenem resistance in $P$. aeruginosa has increased worldwide and has become of great concern since it significantly restricts the therapeutic options for patients (El Solh and Alhajhusain, 2009). Carbapenem resistance in $P$. aeruginosa is caused by chromosomal substitutions resulting in membrane permeability alterations through porin loss and efflux pump overexpression, together with intrinsic beta-lactamase derepression, and the acquisition of the genes for carbapenemases (Livermore, 1992; Masuda et al., 2000; Lister et al., 2009).

In this review, we summarized carbapenem resistance in $P$. aeruginosa. The first half of this review outlines the worldwide epidemiology and the second half discusses the mechanisms of carbapenem resistance and the mobile genetic elements responsible for the horizontal dissemination of resistance determinants. All of the information in the review was collected and analyzed from the National Database of Antibiotic Resistant Organisms ${ }^{1}$ using the Reference Gene Catalog ver. 2020-09-22.2 2 for the carbapenemases and the Genome Database (last updated on 22 September 2020$)^{3}$ for the complete P. aeruginosa genomes.

\section{CARBAPENEMS FOR ANTIPSEUDOMONAL TREATMENT AND RESISTANCE IN $P$. aeruginosa}

\section{Carbapenems for the Treatment of Patients With $P$. aeruginosa Infection}

Beta-lactams act by binding to and inactivating the penicillinbinding proteins (PBPs), which have an essential role for the completion of peptidoglycan biosynthesis through their dual activity as a transglycosylase and transpeptidase. Among the beta-lactams, carbapenems are the most effective against Gram-positive and Gram-negative bacteria, presenting a broad spectrum of antibacterial activity. Replacing the sulfur atom at the $\mathrm{C}-1$ position of the penicillin backbone by a carbon atom (the red dot of the carbapenem backbone in the box in Figure 1) allows exceptional stability against most enzymes inactivating beta-lactams (Papp-Wallace et al., 2011).

The early carbapenem ertapenem has a bulky R3 moiety, resulting in a weak affinity to the PBP3 of $P$. aeruginosa, and consequently, the drug has little activity against $P$. aeruginosa (Figure 1). Thus, the late carbapenems imipenem and meropenem are actively used for the treatment of infections (Luyt et al., 2014). Among the three antipseudomonal carbapenems, imipenem has a distinctive stereographic structure and the

\footnotetext{
${ }^{1}$ https://www.ncbi.nlm.nih.gov/pathogens/antimicrobial-resistance/

${ }^{2}$ https://www.ncbi.nlm.nih.gov/pathogens/isolates\#/refgene/

${ }^{3}$ https://www.ncbi.nlm.nih.gov/genome/
}

lowest minimum inhibitory concentrations (MICs) for wild $P$. aeruginosa strains (Figure 1). Meropenem presents good affinity to the active site of PBP3 (Figure 2). The recently developed combinations of beta-lactam/beta-lactamase inhibitor, such as aztreonam-avibactam, meropenem-vaborbactam, and imipenem-relebactam, have a limited efficacy against the metallo-beta-lactamase (MBL)-producing carbapenemresistant $P$. aeruginosa (Karlowsky et al., 2017, 2020; Lob et al., 2020). However, the siderophore cephalosporin cefiderocol (Delgado-Valverde et al., 2020) is effective against all the carbapenemase-producing $P$. aeruginosa, including the MBL producers.

\section{Carbapenem Resistance in $P$. aeruginosa}

The rate of carbapenem resistance in $P$. aeruginosa varies worldwide (Figure 3). According to the Antimicrobial Testing Leadership and Surveillance program by Pfizer in 2018 (last updated on September 14, 2020) (Pfizer, 2020), the rate of resistant clinical strains $(-\mathrm{R})$ of $P$. aeruginosa by continent was the lowest in Oceania (imipenem- $\mathrm{R}$ in $7.1 \%$ and meropenem$\mathrm{R}$ in $5.1 \%$ of 99 isolates from Australia), and the highest was in the Middle East (imipenem- $\mathrm{R}$ in $27.9 \%$ and meropenem- $\mathrm{R}$ in $19.5 \%$ of 226 isolates from four participating countries). In descending order, the median resistance rates were $30.7 \%$ in South America (the lowest imipenem-R and meropenem- $\mathrm{R}$ both in $12.5 \%$ of 24 isolates from the Dominican Republic and the highest imipenem- $\mathrm{R}$ in $49.3 \%$ and meropenem- $\mathrm{R}$ in $75.3 \%$ in 75 isolates from Chile, among nine participating countries), $28.0 \%$ in Europe (the lowest $0.0 \%$ of 19 isolates from Finland and the highest imipenem- $\mathrm{R}$ in $48.5 \%$ and meropenem- $\mathrm{R}$ in $44.8 \%$ of 194 isolates from Russia, among 24 participating countries), $24.4 \%$ in North America (imipenem- $\mathrm{R}$ in $21.4 \%$ and meropenem$\mathrm{R}$ in $18.3 \%$ of 197 isolates from Canada and imipenem- $\mathrm{R}$ in $27.4 \%$ and meropenem- $\mathrm{R}$ in $15.5 \%$ of 588 isolates from the United States), $22.8 \%$ in Africa (the lowest imipenem-R in $13.2 \%$ and meropenem- $\mathrm{R}$ in $15.8 \%$ of 38 isolates from Nigeria and the highest imipenem- $\mathrm{R}$ in $21.4 \%$ and meropenem- $\mathrm{R}$ in $19.4 \%$ of 98 isolates from South Africa, among three participating countries), and $18.1 \%$ in Asia (the lowest imipenem- $\mathrm{R}$ and meropenem- $\mathrm{R}$ both in $8.0 \%$ of 75 isolates from Japan and the highest imipenem$\mathrm{R}$ in $33.2 \%$ and meropenem- $\mathrm{R}$ in $25.1 \%$ of 386 isolates from China, among 10 participating countries).

\section{Epidemic High-Risk $P$. aeruginosa Clones}

The current $P$. aeruginosa high-risk clones, which meet both requirements of global dominance and association with the multidrug-resistant phenotype, include $10 \mathrm{P}$. aeruginosa lineages belonging to ST111, ST175, ST233, ST235, ST244, ST277, ST298 (CC445), ST308, ST357, and ST654 (Del Barrio-Tofino et al., 2020). The multidrug-resistant $P$. aeruginosa ST111, ST175, and ST235 have been identified to carry genomic islands (Roy Chowdhury et al., 2017). While all the 10 high-risk clones are relevant to MBL production, ST235 and ST111 are by far the most worrisome carbapenemase producers, associated not only with class $\mathrm{B}$ but also with class $\mathrm{A}$ and 


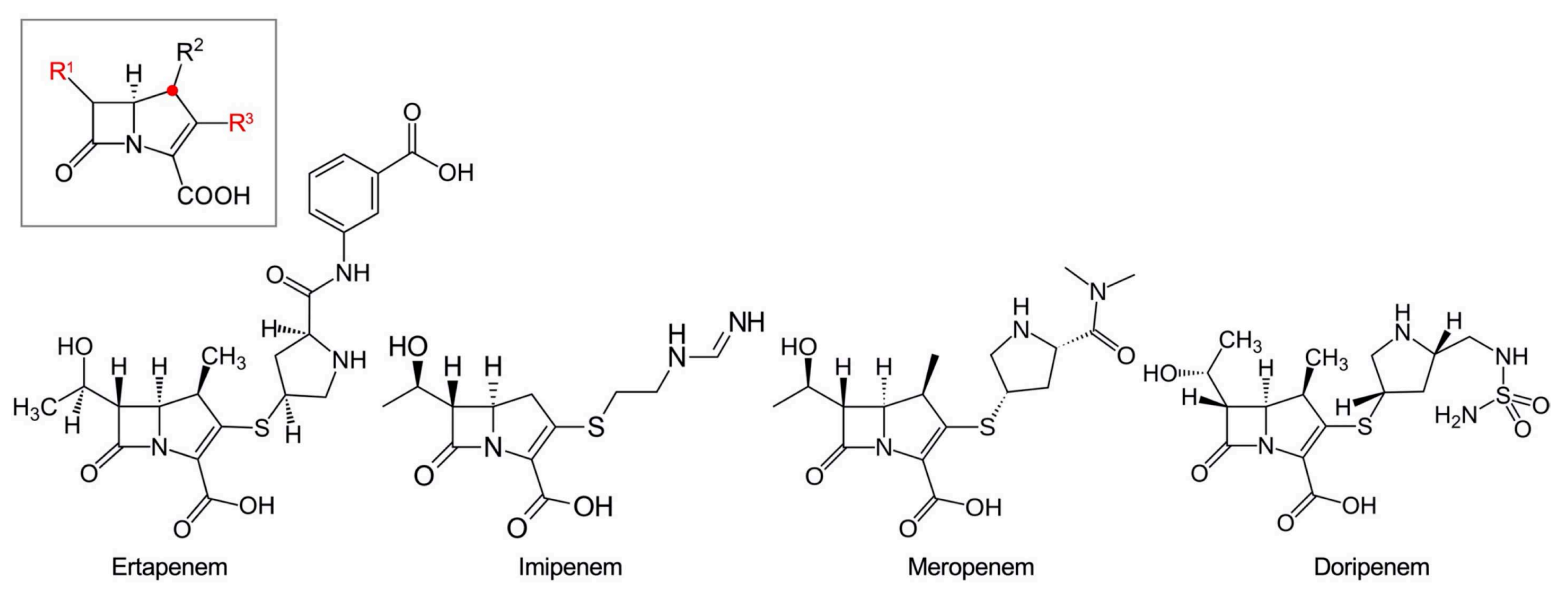

FIGURE 1 | Carbapenem drugs. The backbone of carbapenems is in a box. The C-1 position replaced from the sulfur atom in the penicillin backbone is indicated with a red dot. The important R1 and R3 positions are indicated with red letters. Ertapenem with a bulky R3 residue, which does not have enough affinity to be active against Pseudomonas aeruginosa, is presented with the other three carbapenems having antipseudomonal activity.

D carbapenemases. The widespread $P$. aeruginosa ST235 clone is often associated with poor clinical outcomes due to its multidrug resistance and virulence factors, representatively the cytotoxin ExoU causing necrotic cell death (Sato et al., 2003; Roy Chowdhury et al., 2016; Yoon et al., 2019). The second dominant $P$. aeruginosa clone is ST111, which has been identified in all six continents except Oceania (Del Barrio-Tofino et al., 2020).

\section{MECHANISMS OF RESISTANCE TO CARBAPENEMS IN $P$. aeruginosa}

\section{Chromosomal Mutation-Derived Carbapenem Resistance}

Pseudomonas aeruginosa can acquire resistance to carbapenems by chromosomal mutations (Lister et al., 2009). Loss of the outer membrane protein OprD, which is a channel for imipenem penetration (Margaret et al., 1989), is associated with a reduced susceptibility to carbapenems, mostly imipenem (Farra et al., 2008). Early reports have underlined OprD deficiency as the predominant mechanism of carbapenem resistance in $P$. aeruginosa (Margaret et al., 1989; Kohler et al., 1999). The overexpression of efflux pump systems, such as MexAB-OprM, by mutation at the regulatory region contributes directly to the resistance to meropenem (Kohler et al., 1999; Masuda et al., 2000) and mutational derepression of the chromosomal cephalosporinase AmpC, especially the extendedspectrum cephalosporinases (Rodriguez-Martinez et al., 2009a), and plays a part in carbapenem resistance (Quale et al., 2006; Rodriguez-Martinez et al., 2009b). The combination of porin loss, efflux pump overexpression, and chromosomal cephalosporinase derepression is able to confer high-level resistance to carbapenems, and $P$. aeruginosa could have elevated imipenem and meropenem MICs up to 256 and $128 \mathrm{mg} / \mathrm{L}$, respectively (Chalhoub et al., 2016).

\section{Enzymatic Mechanisms of Carbapenem Resistance}

Before 1990, the only known mechanism of carbapenem resistance was mutations occurring in the chromosome. Following the first identification of an MBL-producing $P$. aeruginosa clinical strain (Watanabe et al., 1991; Minami et al., 1996), a retrospective screening of $P$. aeruginosa identified the bla IMP-1 $_{\text {gene in }} 1992$ in Japan (Senda et al., 1996a). Subsequent outbreaks due to the transferable drug resistance conferred by the gene were reported (Senda et al., 1996b). The bla $a_{\mathrm{VIM}-1}$ gene encoding the Verona integron-encoded $\mathrm{MBL}$ (VIM) subtype 1 in $P$. aeruginosa clinical strain was identified in 1997 in Italy in a $P$. aeruginosa clinical isolate (Lauretti et al., 1999). And the carbapenem-resistant $P$. aeruginosa spread rapidly through the contribution of mobile genetic elements and high-risk clones. Thus far, class A, B, and D carbapenemases have been identified in $P$. aeruginosa, and the class B MBL enzyme is the most prevalent (Queenan and Bush, 2007).

\section{Class A Beta-Lactamases}

The class A beta-lactamases include serine at amino acid (aa) 70 at the active site and the general base Glu-166 is involved in the catalytic process, which makes a difference from the other serine beta-lactamases of classes C and D (Matagne et al., 1999). In $P$. aeruginosa, the Klebsiella pneumoniae carbapenemase (KPC) and the Guiana extended-spectrum beta-lactamase (GES) belonging to the class A beta-lactamases with carbapenemase activity have been identified. The class A carbapenemases actively hydrolyze carbapenems and are partially inhibited by clavulanic acid.

Klebsiella pneumoniae carbapenemase was first discovered in a $K$. pneumoniae clinical isolate from North Carolina, United States, in 1996, presenting a specific pattern of resistance to penicillins, extended-spectrum cephalosporins, and aztreonam (Yigit et al., 2001). The first KPC-producing P. aeruginosa isolate was identified in Colombia in Villegas et al. (2007), and 

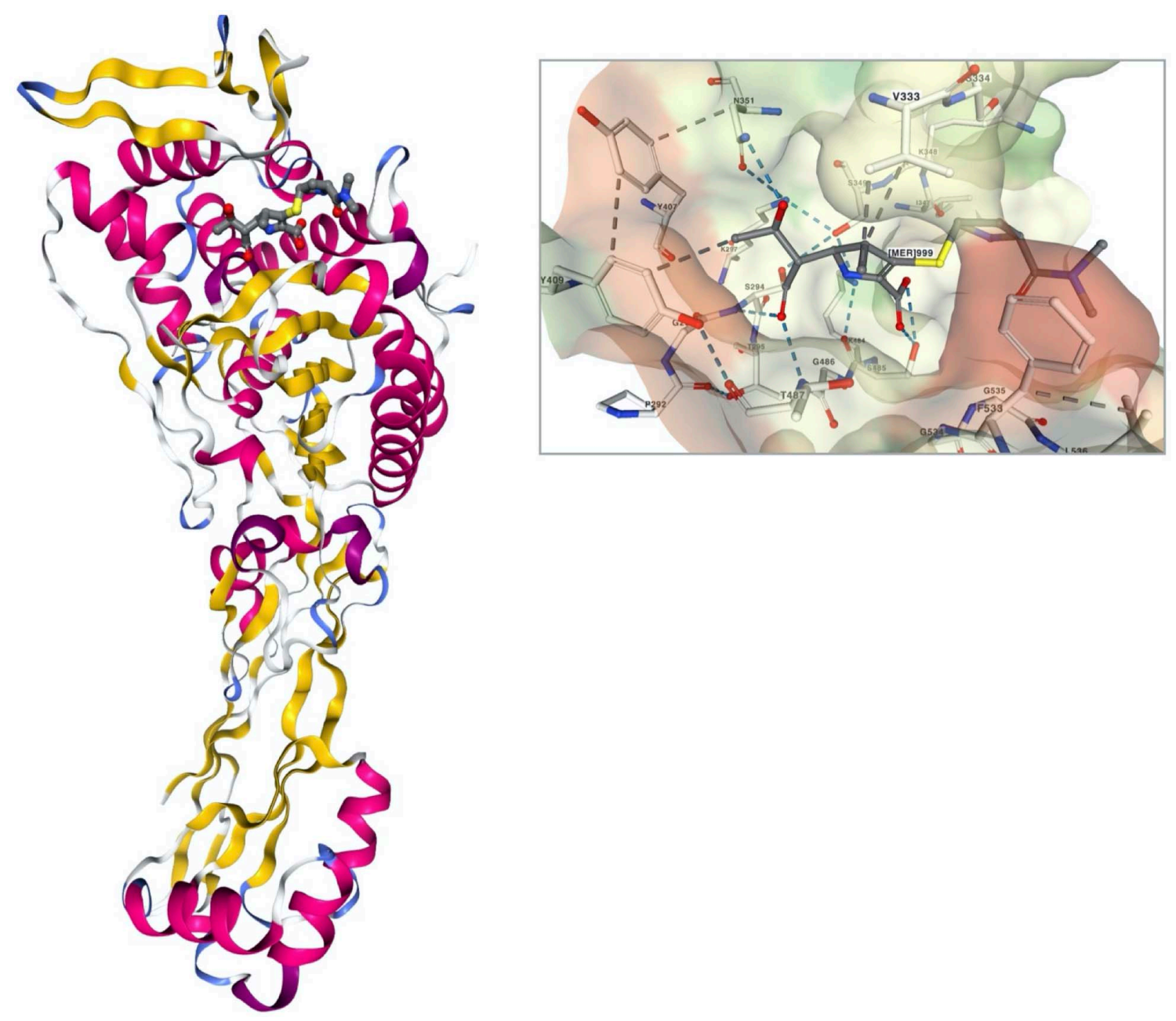

FIGURE 2 | A stereoview of PBP3 of Pseudomonas aeruginosa complexed with meropenem (PDB ID, 3PBR) and the interaction of the meropenem in the ligand pocket of PBP3 (Han et al., 2010). The structure of PBP3 is colored by secondary structure, and the meropenem is in a ball-and-stick presentation. The molecular surface of PBP3 in the binding pocket is presented with the interacting amino acid residue complex with meropenem in a ball-and-stick presentation.

subsequent reports of the pathogen followed all over the world, including America (Akpaka et al., 2009; Poirel et al., 2010; Robledo et al., 2011; Jacome et al., 2012; Ramirez et al., 2013; Kazmierczak et al., 2016a; Walkty et al., 2019), Asia (Ge et al., 2011; Paul et al., 2015; Falahat et al., 2016; Hagemann et al., 2018), and Europe (Figure 4).

Among the GES-type class A beta-lactamases, only the variants with alterations at aa 170 from glycine to asparagine or serine with a polar uncharged side chain are able to hydrolyze carbapenems (Frase et al., 2009). Among the 43 GES variants, subtypes $4-6,14-16,18,20,21,24,25,27-30,33,34,36$, $37,39,40-42$, and 43 with serine at aa 170 and variants 2 and 13 with asparagine at aa 170 have carbapenem-hydrolyzing activity. Of note is that variant 22 , having a substitution to leucine with a hydrophobic side chain at aa 170, does not confer resistance to carbapenems (Castanheira et al., 2014a). GES-type carbapenemase-producing $P$. aeruginosa has been identified in North and South America [Canada (McCracken et al., 2019),
Mexico (Treepong et al., 2018), and Brazil (Polotto et al., 2012)], in Europe [including Belgium (Bebrone et al., 2013), Turkey (Malkocoglu et al., 2017), Spain (Viedma et al., 2009; Treepong et al., 2018), and Russia (Treepong et al., 2018)], in Africa [South Africa (Poirel et al., 2001); in the Middle East of Lebanon (Yaghi et al., 2019)], in Asia [including Japan (Hishinuma et al., 2018), India (Maurya et al., 2014), China (Wang et al., 2006a), and South Korea (Hong et al., 2016; Jabalameli et al., 2018)], and in Oceania [Australia (Sherry et al., 2018)] (Figure 4).

The carbapenem-hydrolyzing class A beta-lactamase producers mostly belong to ST235, ST111, ST357, and ST463. The KPC-, and GES-5-producing P. aeruginosa clones have been identified in Europe [Spain (Viedma et al., 2009), Italy (Giani et al., 2018), Lithuania (Mikucionyte et al., 2016), Turkey, Germany (Castanheira et al., 2014b), Belarus, and Russia (Edelstein et al., 2013)] and in Asian countries [Kazakhstan (Edelstein et al., 2013), Thailand (Khuntayaporn et al., 2019), 


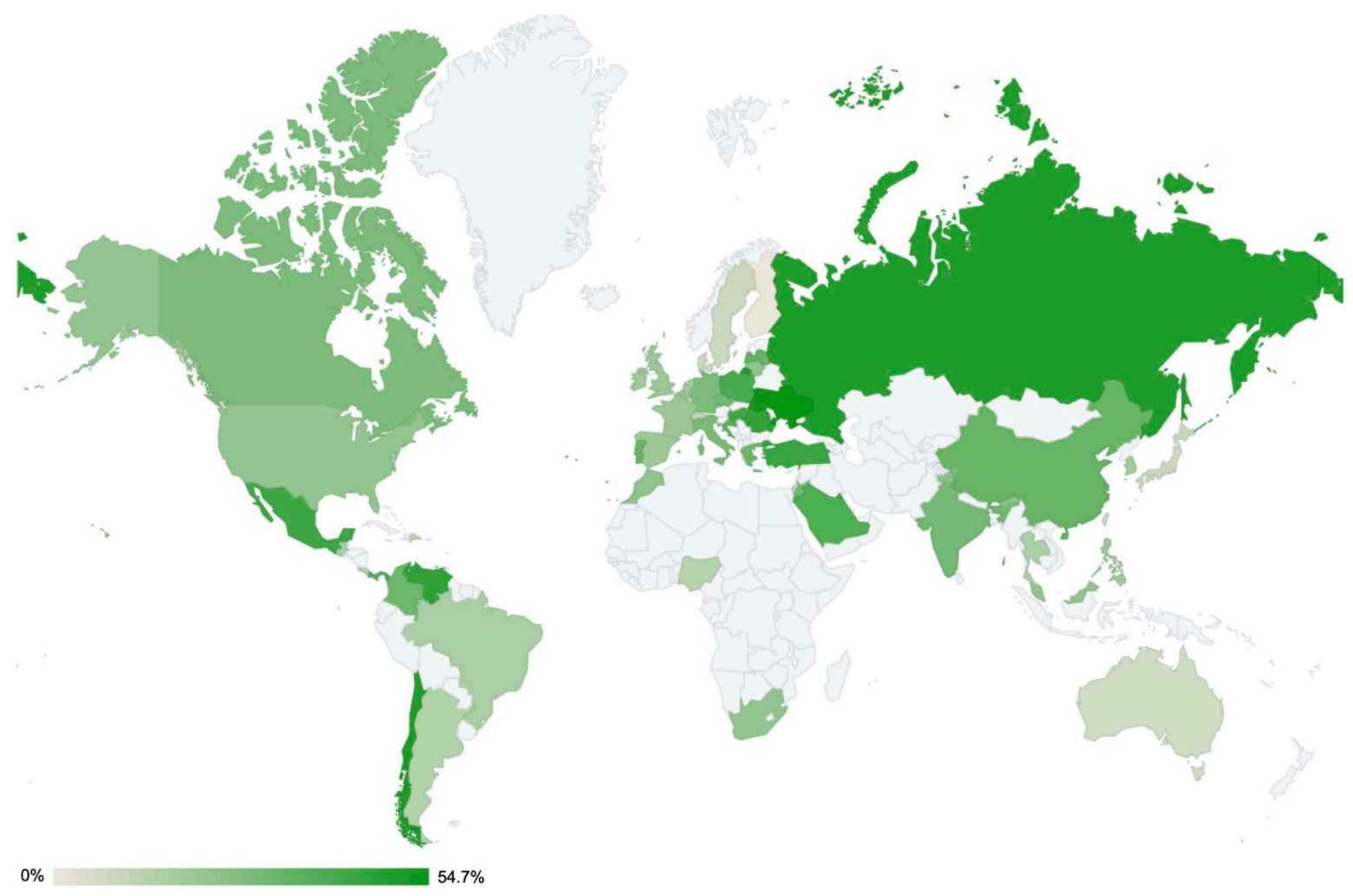

FIGURE 3 | Rates of imipenem resistance in Pseudomonas aeruginosa worldwide in 2018. All the data were extracted from the Antimicrobial Testing Leadership and Surveillance run by Pfizer (last updated on October 30, 2019) (Pfizer, 2020), except for the data from South Korea (unpublished data). The actual resistance rates are indicated per continent as follows: Africa [three participating countries: Morocco $(N=79,22.8 \%)$, Nigeria $(N=38,13.2 \%)$, South Africa $(N=98,21.4 \%)$ ]; Asia [10 participating countries: China $(N=386,33.2 \%)$, Hong Kong $(N=25,24 \%)$, India $(N=125,29.6 \%)$, Japan $(N=75,8 \%)$, Malaysia $(N=55,21.8 \%)$, Philippines $(N=74,18.9 \%)$, Singapore $(N=25,16 \%)$, South Korea $(N=127,18.1 \%)$, Taiwan $(N=99,9.1 \%)$, and Thailand $(N=75,16 \%)]$; Europe [24 participating countries: Belgium $(N=150,21.3 \%)$, Croatia $(N=78,35.9 \%)$, Czech Republic $(N=102,29.4 \%)$, Denmark $(N=25,8 \%)$, Finland $(N=19,0 \%)$, France $(N=248,20.2 \%)$, Germany $(N=248,27.4 \%)$, Greece $(N=75,30.7 \%)$, Hungary $(N=100,42 \%)$, Ireland $(N=64,18.8 \%)$, Italy $(N=242,28.5 \%)$, Latvia $(N=24,33.3 \%)$, Lithuania $(N=50,22 \%)$, Poland $(N=101,39.6 \%)$, Portugal $(N=99,32.3 \%)$, Romania $(N=99,45.5 \%)$, Russia $(N=194,48.5 \%)$, Netherlands $(N=40$, $17.5 \%)$, Spain $(N=273,19.4 \%)$, Sweden $(N=25,8 \%)$, Switzerland $(N=50,10 \%)$, Turkey $(N=60,43.3 \%)$, Ukraine $(N=53,54.7 \%)$, and United Kingdom $(N=158,19.6 \%)$; Mid and South America [10 participating countries: Brazil $(N=116,16.4 \%)$, Chile $(N=75,49.3 \%)$, Colombia $(N=124,30.7 \%)$, Costa Rica $(N=22,13.6 \%)$, Dominican Republic $(N=24,12.5 \%)$, Guatemala $(N=55,16.4 \%)$, Mexico $(N=146,42.5 \%)$, Panama $(N=32,37.5 \%)$, and Venezuela $(N=64,45.3 \%)$ ]; North America [two participating countries: Canada $(N=197,27.4 \%)$ and the United States $(N=588,21.4 \%)$,]; Middle East [four participating countries: Israel ( $N=100,12 \%)$, Jordan $(N=24,29.2 \%)$, Kuwait $(N=76,44.7 \%)$, and Saudi Arabia $(N=26,38.5 \%)$; and Oceania [a single participating country: Australia $(N=99,7.1 \%)$.

China (Hu et al., 2015), and South Korea (Hong et al., 2016)] (Figure 5).

\section{Class B Beta-Lactamases}

The class B beta-lactamases are also known as "metallo-" betalactamases because they need divalent cations, usually $\mathrm{Zn}^{2+}$ ions, as a metal cofactor to hydrolyze beta-lactams. Although class B beta-lactamases are subclassified as B1, B2, and B3 based on structural and functional points (Frere et al., 2005), we will discuss subclass B1, the only dominant subclass in $P$. aeruginosa. The B1 subclass contains the largest number of clinically relevant acquired MBLs, not only in P. aeruginosa but also in Enterobacterales and other Gram-negative nonfermenters. MBLs bind two $\mathrm{Zn}^{2+}$ atoms for optimal hydrolysis. $\mathrm{Zn}^{2+}$ ion ligands bind at $3 \mathrm{H}$ (His-His-His) and DCH (AspCys-His) sites, and the binding of di- $\mathrm{Zn}^{2+}$ plays a critical role in hydrolyzing beta-lactam substrates (Frere et al., 2005; MoranBarrio et al., 2016). Consequently, the carbapenemase activity of MBLs is diminished in the presence of a chelator of $\mathrm{Zn}^{2+}$ and other divalent cations, i.e., ethylenediaminetetraacetic acid (EDTA). The substrate profile of the MBLs includes penicillins, cephalosporins, and carbapenems, but excludes monobactams. The acquired MBL genes, located mostly within a class 1 integron as gene cassettes, have been found in various bacterial species, including $P$. aeruginosa.

Metallo-beta-lactamase are the most prevalent type of carbapenemases produced by $P$. aeruginosa clinical isolates. VIMs are the most disseminated, followed by imipenemases (IMPs). New Delhi MBLs (NDMs) have also been identified. Regional dissemination of $P$. aeruginosa clinical strains producing Australian imipenemase (AIM), Central Alberta MBL (CAM), Dutch imipenemase (DIM), Florence imipenemase (FIM), German imipenemase (GIM), Hamburg MBL (HMB), 
A Class A

KPC
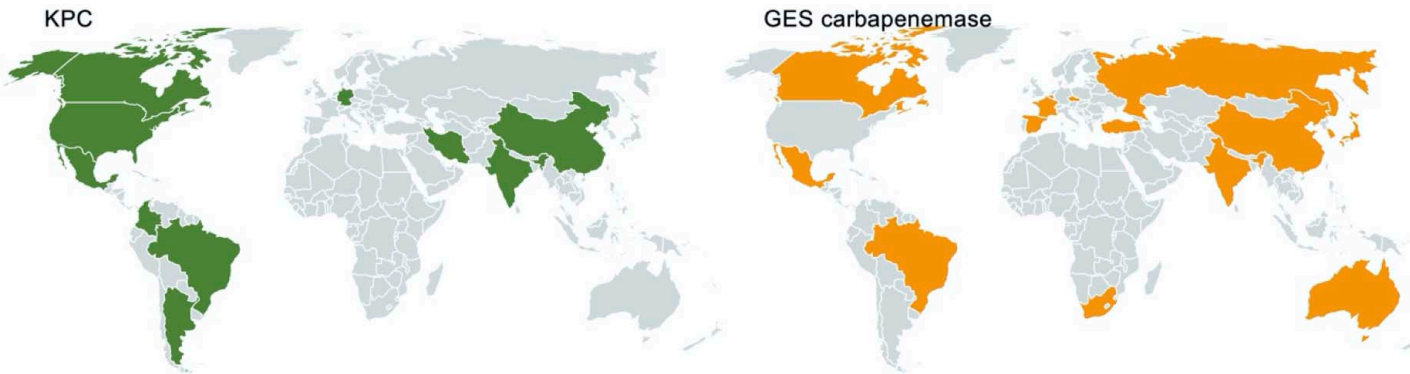

B Class B
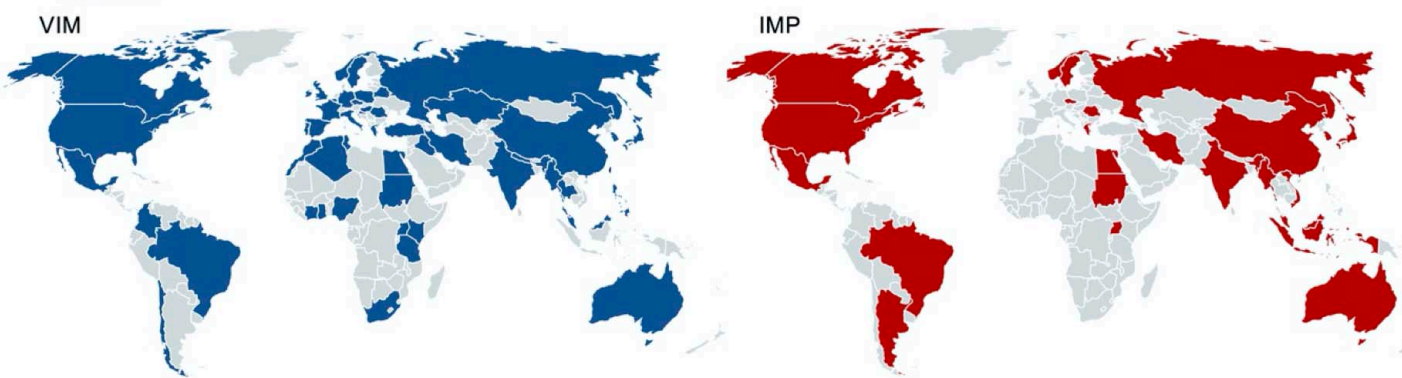

NDM
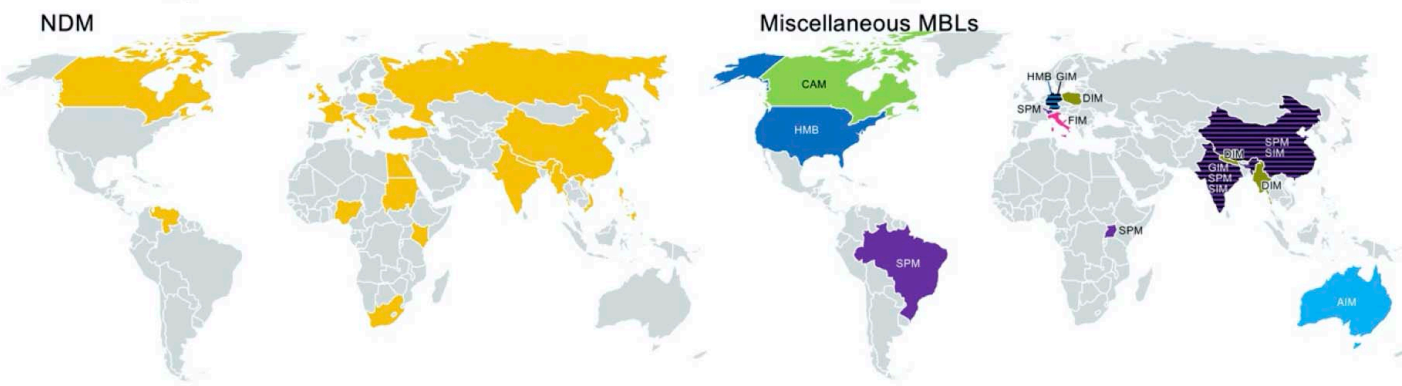

\section{Class D}

OXA carbapenemase

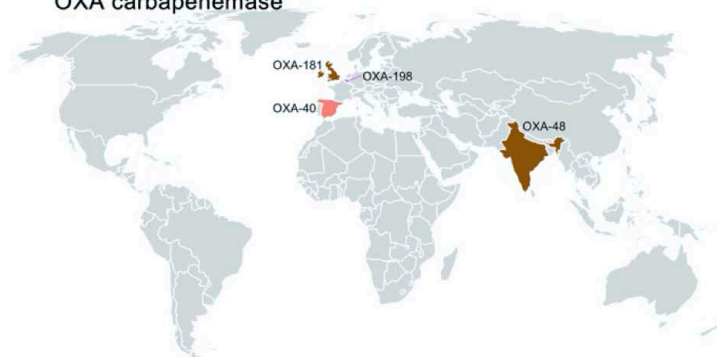

FIGURE 4 | Worldwide identification of the carbapenemase-producing Pseudomonas aeruginosa. Reports of class A [Klebsiella pneumoniae carbapenemase (KPC) and Guiana extended-spectrum beta-lactamase (GES) with amino acid alteration at aa 170], class B [Verona integron-encoded MBL (VIM), imipenemase (IMP), New Delhi MBL (NDM), and others], and class D (OXA) carbapenemases are indicated in a geographic map. The references used for the map drawing are indicated in the main text.

São Paulo MBL (SPM), and Seoul imipenemase (SIM) was also reported.

A VIM-1-producing $P$. aeruginosa strain was first isolated in Verona, Italy, in Lauretti et al. (1999). Together with subtype VIM-2 (Poirel et al., 2000), the first two VIM enzymes were originally found in $P$. aeruginosa as gene cassettes of class 1 integrons. Notably, VIM-2 has a 10-fold more efficient hydrolyzing activity to both imipenem and meropenem compared to VIM-1 (Docquier et al., 2003), and in most of the countries, VIM-2 is the dominant carbapenemase produced by 


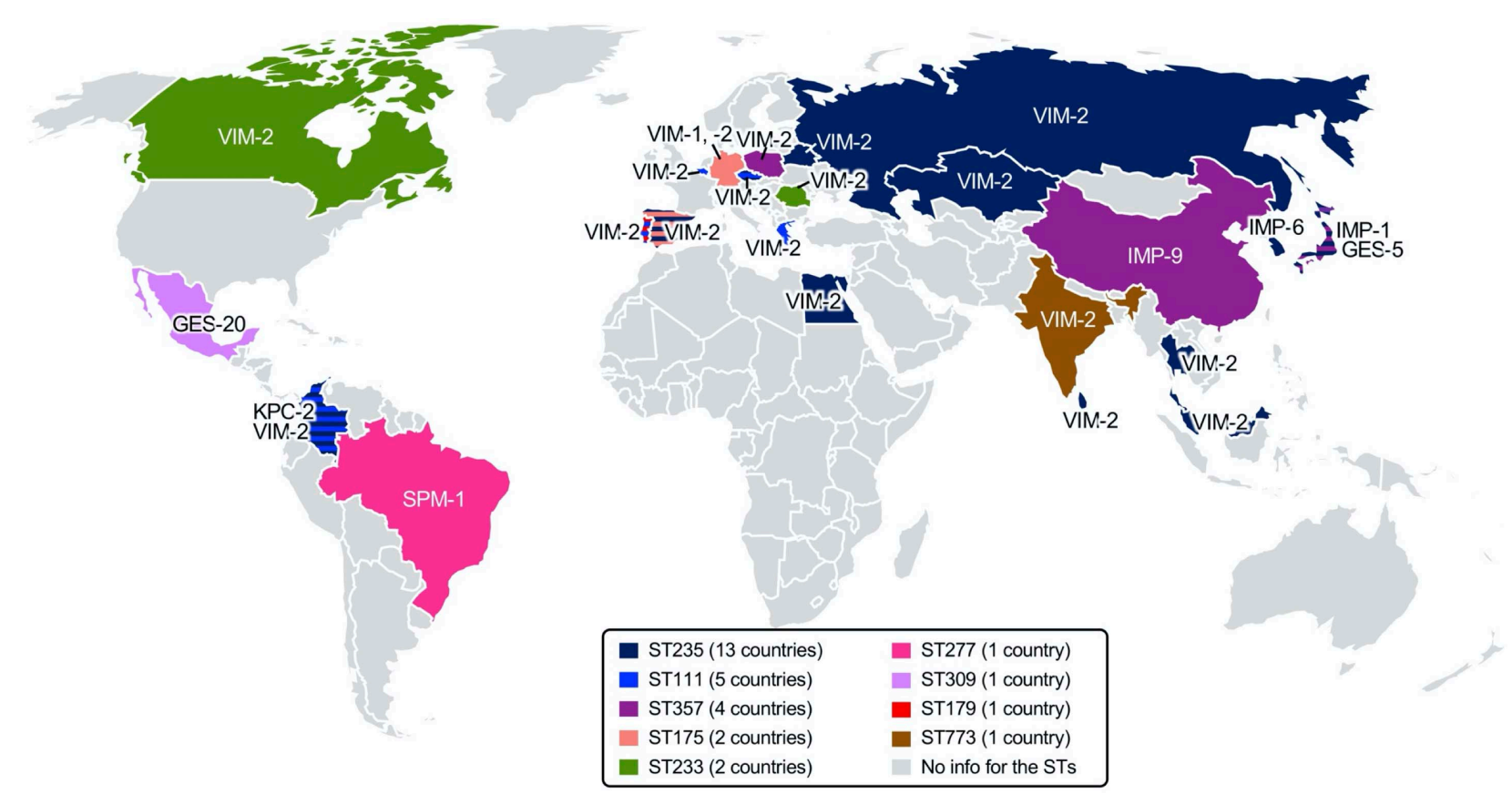

FIGURE 5 | Epidemic carbapenemase-producing high-risk Pseudomonas aeruginosa clones identified worldwide. Regional dissemination of specific $P$. aeruginosa clones identified through multilocus sequence typing (MLST) is indicated in color on a geographic map, and the carbapenemases produced are indicated at the region. The number of countries with reports of the $P$. aeruginosa clone are indicated in the figure legends. References are indicated in the main text.

P. aeruginosa (Kazmierczak et al., 2016b). Thus far, a total of 66 variants of VIM have been identified, and subtype 2-producing $P$. aeruginosa has been extensively spread, with a few regional exceptions by specific outbreaks. VIM-producing $P$. aeruginosa clinical strains have been identified in almost all countries reporting surveillance data in six continents: in Europe (Poirel et al., 2000; Pournaras et al., 2002; Bahar et al., 2004; Deplano et al., 2007; Juan et al., 2008; Schneider et al., 2008; Siarkou et al., 2009; Bosnjak et al., 2010; Samuelsen et al., 2010; Mazzariol et al., 2011; Edelstein et al., 2013; Dortet et al., 2015; Kazmierczak et al., 2016b), in Asia (Wang et al., 2006b; Khosravi and Mihani, 2008; Nho et al., 2008; Al-Agamy et al., 2009; Castanheira et al., 2009; Azim et al., 2010; Khosravi et al., 2010; Koh et al., 2010; Mano et al., 2015; Kazmierczak et al., 2016b; Tada et al., 2017, 2019; Tohya et al., 2019; Yaghi et al., 2019), in North (Toleman et al., 2004; Pitout et al., 2007) and South America (Crespo et al., 2004; Pasteran et al., 2005; Kazmierczak et al., 2016a; Rios et al., 2018; Pacheco et al., 2019), in Africa (Pitout et al., 2008; Ktari et al., 2011; Jeannot et al., 2013; Moyo et al., 2015; Kateete et al., 2016; Adam and Elhag, 2018), and in Oceania (Tai et al., 2015; Figure 4). P. aeruginosa ST111 mostly produces VIM-2 and has been identified in European countries [the Czech Republic (Papagiannitsis et al., 2017), Portugal (Botelho et al., 2018), Italy (Giani et al., 2018), Greece, and Belgium (Castanheira et al., 2014b)] and in Latin American countries [Colombia (Correa et al., 2015)]. Less frequently, VIM-producing $P$. aeruginosa ST244 was identified in China (Chen et al., 2014; Feng et al., 2017), Brazil (de Oliveira Santos et al., 2019), and Africa (Cholley et al., 2014); VIM-producing P. aeruginosa ST175 was identified in Europe [Spain and Germany (Elias et al., 2010; Garcia-Castillo et al., 2011; Viedma et al., 2012; Giani et al., 2018)].

After the first IMP enzyme found in Japan in Watanabe et al. (1991), subsequent interspecies spread of the bla IMP gene to Enterobacterales and Acinetobacter baumannii was reported in Japan and Europe, respectively (Arakawa et al., 1995). Currently, up to 79 variants of IMP have been identified, and varied subtypes have been identified with regional inconsistency. The global prevalent subtype is IMP-1, with a few exceptions of IMP-9 in China (Xiong et al., 2006) and IMP-6 in South Korea (Ryoo et al., 2009). Notably, IMP-6 has better hydrolyzing activity to meropenem than to imipenem compared to the other subtypes of IMP enzymes (Yano et al., 2001). IMP is the second most common carbapenemase produced by $P$. aeruginosa regardless of whether the strain was isolated in Europe (Hrabak et al., 2009, 2011; Samuelsen et al., 2010), in Asia (Xiong et al., 2006; Kouda et al., 2007; Nho et al., 2008; Ryoo et al., 2009; Azim et al., 2010; Khosravi et al., 2010; Koh et al., 2010; Tada et al., 2019; Yaghi et al., 2019), in North (Gibb et al., 2002; Hanson et al., 2006), and South America (Garza-Ramos et al., 2008; Kazmierczak et al., 2016b), in Africa (Kateete et al., 2016; Adam and Elhag, 2018), and in Oceania (McCarthy et al., 2017; Figure 4). P. aeruginosa ST357 mostly produces IMP. The clone was spread in Europe (Hrabak et al., 2011; Papagiannitsis et al., 2017) and Asia (Kouda et al., 2009; Fan et al., 2016). IMP-producing P. aeruginosa ST621 was identified in Europe [Italy (Giani et al., 2018) and France (Fournier et al., 2012)] (Figure 5).

The NDM enzyme was first identified in 2008 in K. pneumoniae isolated from a Swedish patient with a history 
of travel to India (Yong et al., 2009). Shortly after, the NDM producers became endemic in South Asian countries located in the Indian subcontinent, such as India, Pakistan, and Bangladesh (Kumarasamy et al., 2010; Dortet et al., 2014). The first report of NDM-1-producing $P$. aeruginosa was in Serbia in Jovcic et al. (2011), and subsequent dissemination was observed in the Balkans (Jovcic et al., 2013; Kulkova et al., 2015). NDMproducing $P$. aeruginosa has been identified mostly in Asia (Khajuria et al., 2013; Paul et al., 2015; Tada et al., 2017, 2019; Honda et al., 2019; Tohya et al., 2019), in Europe (Jovcic et al., 2011; Carattoli et al., 2013; Janvier et al., 2013; Kulkova et al., 2015; Urbanowicz et al., 2019), and in Africa (Manenzhe et al., 2015; Kateete et al., 2016; Adam and Elhag, 2018). And, as a sporadic emergence, it was also identified in North America (Mataseje et al., 2016; Figure 4). Among a total of 27 variants of NDM that have been identified, NDM-1 seems to be the most prevalent subtype.

Being different from the intercontinental dissemination of VIM-, IMP-, and NDM-producing $P$. aeruginosa, other MBLproducing $P$. aeruginosa outbreaks or regional spreading have occurred, except for SPM-producing $P$. aeruginosa. SPMproducing $P$. aeruginosa was first identified in São Paulo, Brazil (Toleman et al., 2002), and the clone belonged to ST277 (Chaves et al., 2017; de Oliveira Santos et al., 2019). The SPM producer was subsequently identified in Switzerland (Salabi et al., 2010), the United Kingdom (Salabi et al., 2010), India (Azim et al., 2010), China (Cai et al., 2016), and Uganda (Kateete et al., 2016; Figure 4). DIM-producing $P$. aeruginosa clinical strains were regionally disseminated mostly in Asia (Tada et al., 2017, 2019) and Europe (Urbanowicz et al., 2019). GIM-producing $P$. aeruginosa was identified in Germany (Castanheira et al., 2004; Wendel et al., 2015) and India (Azim et al., 2010). SIM-producing $P$. aeruginosa was identified in China (Sun et al., 2016). HMB-producing $P$. aeruginosa was identified both in Hamburg, Germany (Pfennigwerth et al., 2017), and in the United States (Walters et al., 2019). CAM-producing P. aeruginosa was identified in Canada (Boyd et al., 2019), and no more dissemination was observed. The AIM and FIM producers were restricted in Australia (Yong et al., 2012) and Italy (Pollini et al., 2013), respectively (Figure 4).

\section{Class D Beta-Lactamases}

Class D beta-lactamases belong to the superfamily of serine betalactamases with a unique carboxylated Lys-73 responsible for the beta-lactam hydrolysis activity (Golemi et al., 2001). The carbapenem-hydrolyzing class D beta-lactamases (CHDLs) were first described in A. baumannii and published by Paton et al. (1993). CHDLs are serine beta-lactamases with a relatively weak activity against carbapenems and are poorly inhibited by EDTA or clavulanic acid. Among a total of 12 groups of CHDLs, three groups-OXA-40-like, OXA-48-like, and OXA-198-like-have been identified in $P$. aeruginosa.

OXA-type carbapenemases are rarely identified in $P$. aeruginosa, and the emergence of the following strains has been reported: OXA-40-producing $P$. aeruginosa in Spain (Sevillano et al., 2009), OXA-48-producing $P$. aeruginosa in India (Borah et al., 2016), OXA-181-producing $P$. aeruginosa in the
United Kingdom (Findlay et al., 2017), and OXA-198-producing P. aeruginosa in Belgium (Bonnin et al., 2018; Figure 4).

\section{MOBILE GENETIC ELEMENTS ASSOCIATED WITH CARBAPENEMASE-ENCODING GENES}

The acquired genes encoding carbapenemases are associated with a plethora of mobile genetic elements, such as plasmids, gene cassettes of integrons, transposons, and genomic islands (Kung et al., 2010). Mobile genetic elements have the ability to move from genome to genome by transformation, conjugation, and transduction, presenting intracellular and intercellular mobility (Roberts et al., 2008).

\section{Pseudomonas aeruginosa Plasmids Carrying the Carbapenemase-Encoding Genes}

In general, the plasmids carrying the carbapenemase-encoding genes in $P$. aeruginosa belong to the distinct incompatibility groups from those in Enterobacterales. Among the 13 known incompatibility types of IncP, IncP-2-type plasmids are classic types frequently identified in $P$. aeruginosa (Korfhagen et al., 1976). Among the 207 complete genomes of $P$. aeruginosa of the Genome Database (NCBI, 2020), five genomes include a plasmid carrying one or two carbapenemase-encoding genes; two of the five plasmids are of the IncP-2 incompatibility type, while the other three are untypable: two $b l a_{\mathrm{KPC}-2}$ genes are harbored by untypable plasmids, which are almost the same (identical nucleotide sequences, except for a 1-bp gap difference between the 57,053- and 57,052-bp plasmids), one bla $a_{\mathrm{VIM}-1}$ is harbored by an untypable plasmid, one IncP-2 plasmid harbors bla $a_{\mathrm{IMP}-45}$, and one IncP-2 plasmid harbors both the bla $a_{\mathrm{VIM}-1}$ and the bla IMP-45 genes. $_{1}$

Among the plasmids in $P$. aeruginosa having an incomplete genome, the 31,529- and 38,939-bp IncP-6 plasmids carrying the $b l a_{\mathrm{KPC}-2}$ gene have been identified in Colombia and China, respectively (Naas et al., 2013; Dai et al., 2016), and the 7,995-bp IncU plasmid including the $b l a_{\mathrm{KPC}-2}$ gene has been identified in Colombia (Naas et al., 2013). An untypable 3,652bp plasmid harboring the bla $a_{\mathrm{KPC}-2}$ gene was identified in Brazil (Galetti et al., 2016).

Recently, a Pseudomonas plasmid lineage carrying the MBL genes has been reported (Di Pilato et al., 2019). A retrospective analysis revealed that the plasmid lineage has been identified since the 1990s, mostly in Europe. While the plasmid does not belong to a recognized plasmid type, the type 4 secretion system components classified the plasmids as MOBF11 or MPFT plasmid families. The MBL genes in the plasmid were identified as gene cassettes of the class 1 integron In70 (Di Pilato et al., 2019).

\section{Carbapenemase-Encoding Gene-Associated Transposable Units}

The carbapenemase-encoding genes are frequently included in transposable elements, which are often associated with the 


\section{$\begin{array}{ll}\text { bla }_{\mathrm{KPC}-2} & \mathrm{EU} 176013 \\ \text { bla }_{\mathrm{NDM}-1} & \mathrm{KC} 170992\end{array}$ \\ KT364224 \\ bla $_{\mathrm{CAM}-1} \quad$ MG430339 \\ bla $_{\mathrm{FIM}-1} \quad \mathrm{JX} 570731$

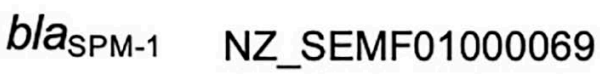

bla AIM-1 $_{\text {AM998375 }}$

bla ${ }_{\mathrm{HMB}-1} \quad \mathrm{KU} 961660$
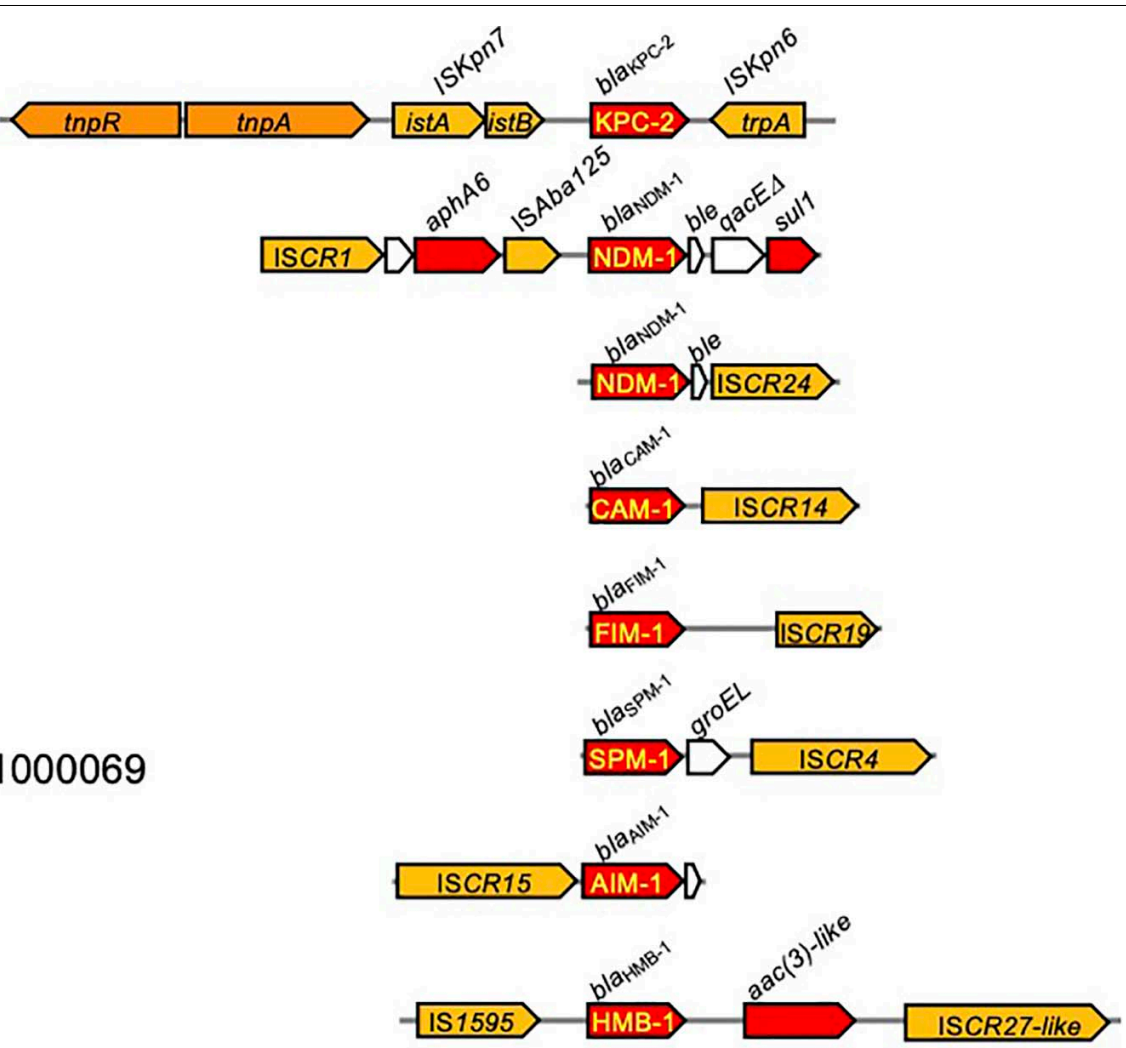

FIGURE 6 | Transposable units identified in Pseudomonas aeruginosa carrying the carbapenemase-encoding genes. The red arrow indicates the genes for antimicrobial resistance, and those with yellow letters inside indicate the genes for carbapenemase. Yellow arrows depict insertion sequences, and those in orange indicate transposase/resolvase.

insertion sequences with a common region (ISCRs) being responsible for the rapid transmission of bacterial multidrug resistance (Figure 6; Toleman et al., 2006). Typically, the ISCR element lacks flanking inverted repeats (IRs) and the integration does not produce direct repeat (DR) sequences (Diaz-Aroca et al., 1987). Rolling circle has been suggested for the transmission mechanism of ISCRs (Figure 7), and the transposition method allows a polarized transfer of the ISCR elements to mobilize adjacent DNA sequences in varied sizes (del Pilar Garcillan-Barcia et al., 2001).

The bla $a_{\mathrm{CAM}}$ and $b l a_{\mathrm{FIM}}$ genes were identified in transposable elements associated with ISCR14 and ISCR19, respectively, located downstream from the gene. The bla $a_{S P M}$ gene was identified in $P$. aeruginosa accompanied with the chaperone groEL gene and flanked by a pair of ISCR4 elements. The $b l a_{\text {AIM }}$ gene was identified in a transposable element associated with the upstream ISCR15. The $b l a_{\mathrm{HMB}-1}$ gene was in a transposable unit, namely, Tn6345 (Supplementary Table 1; Pfennigwerth et al., 2017), flanked by IS1595 upstream and ISCR27-like downstream (Toleman et al., 2006). For the $b l a_{\mathrm{NDM}}$ gene, the composite transposon Tn125 flanked by a pair of ISAba125 copies at both ends has been identified in A. baumannii (Bontron et al., 2016). The bla $a_{\mathrm{NDM}-1}$ geneassociated transposable element is composed of a truncated
Tn125. ISCR is located upstream from the $\triangle \mathrm{ISAba1}$, and downstream of the $b l a_{\mathrm{NDM}-1}$ gene, the ble gene for bleomycin resistance and the $\operatorname{trpF}$ gene for phosphoribosylanthranilate isomerase are followed (Sole et al., 2011).

The Tn4401 carrying the bla $a_{\mathrm{KPC}}$ gene has been found in diverse bacterial hosts, including $P$. aeruginosa (Cuzon et al., 2011; Figure 6). Tn4401 is a 10-kb transposon composed of genes encoding a transposase and a resolvase, and the bla $a_{\mathrm{KPC}}$ gene together with two insertion sequences (ISs), ISKpn6 and ISKpn7 (Figure 6), and transposition of Tn4401 occurs through the mechanism of copy-and-paste replicative transposition (Figure 7; Grindley, 1983). Tn4401 includes nine isoforms from a to I differing in the sequences upstream of the bla $\mathrm{KPC}_{\mathrm{K}}$ gene (Naas et al., 2012; Bryant et al., 2013; Cheruvanky et al., 2017; Araujo et al., 2018; Schweizer et al., 2019). While both Tn4401a and Tn4401b are prevalent in Enterobacterales (Stoesser et al., 2017; Yoon et al., 2018), Tn $4401 b$ is the only isotype identified in $P$. aeruginosa. Seven Tn4401 elements were found through the restricted BLAST against the species $P$. aeruginosa, and all were $\operatorname{Tn} 4401 b$ : two Tn4401b copies in a chromosome (GenBank accession CP029605) and each Tn4401b copy in five plasmids (GenBank accessions MN082782.1, CP027168.1, CP029092.1, KC609323.1, and EU176013.1). 


\section{A Rolling circle}

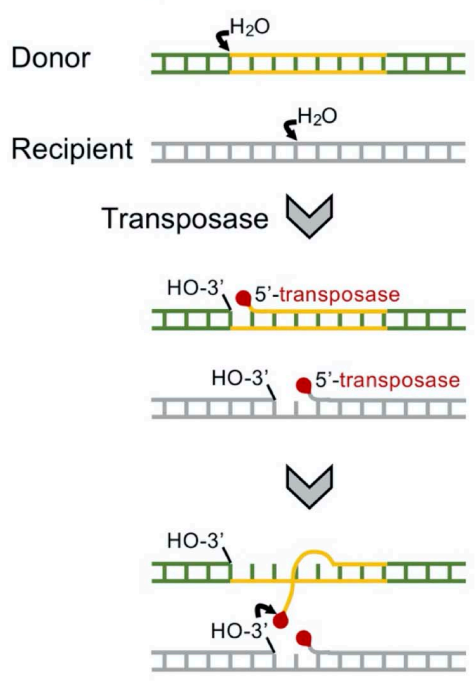

V

HO-3: 5 '-transposase
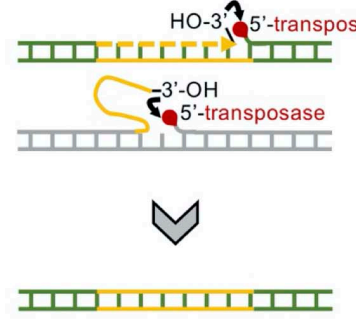

\section{B Copy-and-paste}

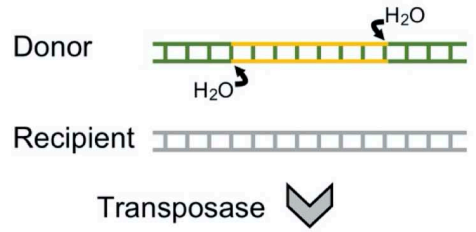

Transposase
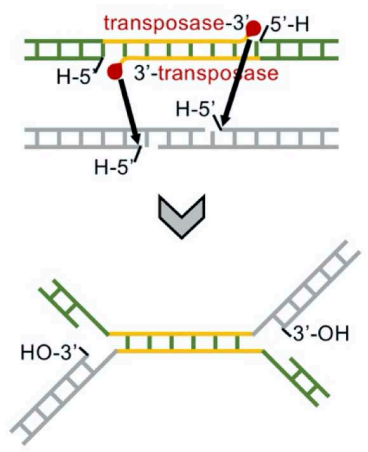

Resolvase

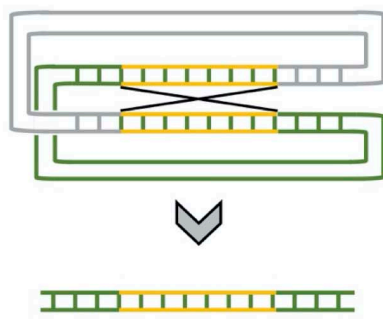

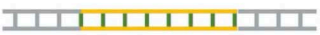

FIGURE 7 | Mechanisms of replicative transposition of the transposons. (A) Insertion sequence with a common region (ISCR)-mediated rolling circle replicative transposition is involved in rolling circle replication. ISCR elements lack terminal inverted repeats, and a single copy of the element is able to transpose adjacent DNA sequences (Toleman et al., 2006). (B) A Tn3-mediated copy-and-paste replicative transposition requires both a transposase and a resolvase. The transposon is replicated, joining the donor and the recipient in a cointegrate, which is resolved to give the donor and the recipient of the transposon (Grindley, 1983).

\section{Class 1 Integrons Carrying Carbapenemase-Encoding Gene Cassettes}

Integrons are assembly platforms comprising an intI gene for a site-specific tyrosine recombinase, an attI for a primary recombination site, the promoter Pc for transcription, and an assemblage of passenger genes composing a gene cassette array (Figure 8; Collis et al., 1993). The IntI integrase recognizes the attC site of the gene cassette and the promoterless gene cassette is inserted as a linear form in the integron (Figure 8; Collis and Hall, 1992). In addition to the catalysis of $a t t C \times a t t C$, the integrase catalyzes attI $\times a t t C$, leading to the gene cassette integration into the attI site. A successive integration of the gene cassettes occurs downstream of the resident Pc promoter (Hall and Collis, 1995). The expression of the gene cassette is dependent on the sole promoter and the level of gene expression depends on the distance from the sole promoter Pc (Coyne et al., 2010). By nature, the first few cassettes are expressed and the rest of the array exists as a reservoir of standing genetic variation (Cambray et al., 2010). Rearrangement of the order of gene cassettes affects the resistance phenotype of the bacterial host (Hall and Collis, 1995; Rowe-Magnus et al., 2002).

\section{Carbapenemase-Encoding Gene Cassettes}

The class A carbapenemase-encoding gene bla $a_{\mathrm{GES}}$, the MBL genes $b l a_{\mathrm{VIM}}, b l a_{\mathrm{IMP}}$, and $b l a_{\mathrm{GIM}-1}$, and the class $\mathrm{D}$ gene $b l a_{\mathrm{OXA}-198}$ were identified as a gene cassette composing a class 1 integron. In the integron database INTEGRALL ( ${ }^{4}$ last updated on 10 December 2020) (Moura et al., 2009), a total of 812 class 1 integrons of 282 different gene cassette arrays were identified for the organism P. aeruginosa. Among them, 191 class 1 integrons of 148 different arrays carried one or two carbapenemase-encoding gene cassettes (Supplementary Table 2). The most prevalent bla $a_{\mathrm{VIM}}$ genes were identified as gene cassettes in 98 arrays of the 130 class 1 integrons. Among them, 13 carried only the bla $\mathrm{VIM}$

${ }^{4}$ http://integrall.bio.ua.pt/ 


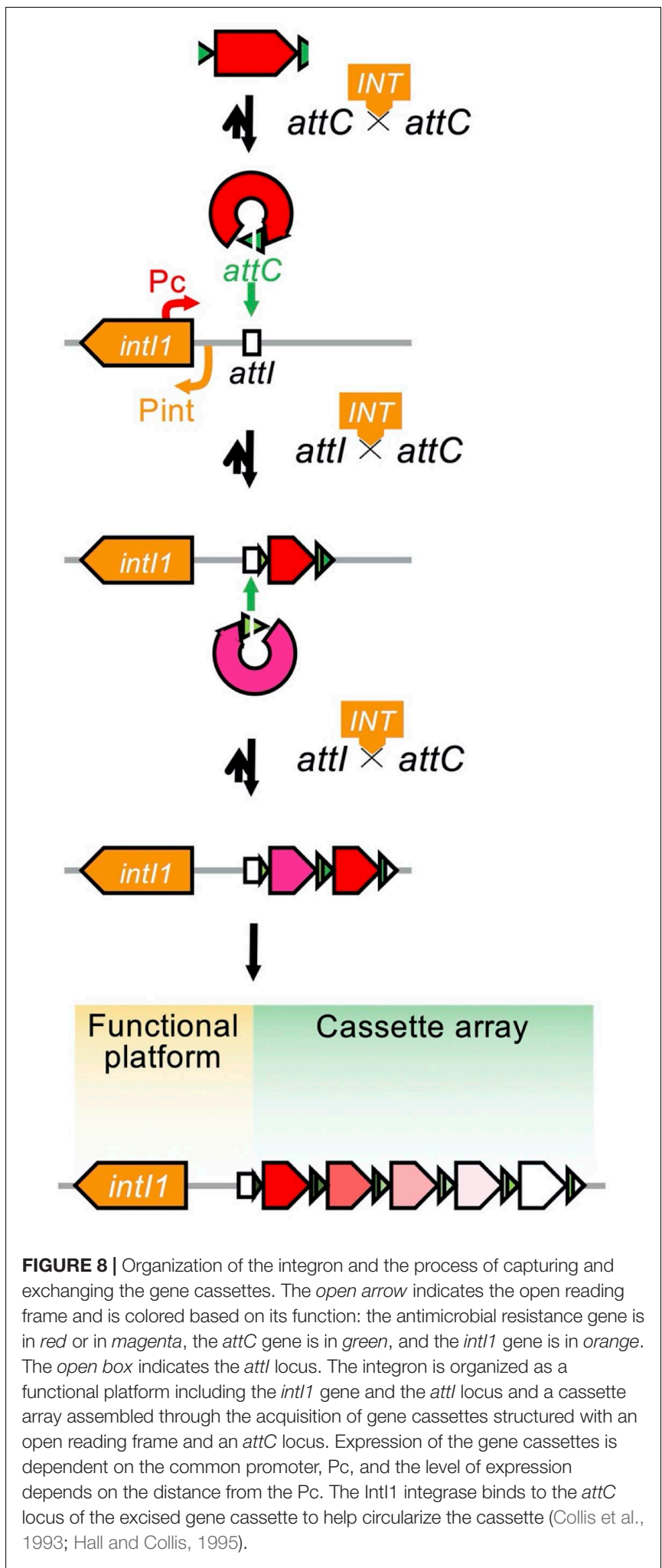

cassette; the others harbored additional gene cassettes encoding aminoglycoside-modifying enzymes, mostly the aacA genes and less frequently the aadA or $a a d B$ genes. All but five carried the bla $a_{\mathrm{VIM}}$ gene cassette in the first position of the array (62.3\%) or in the second position of the array (33.1\%).

The second most dominant $b l a_{\text {IMP }}$ cassettes were identified in 50 class 1 integrons of 40 different arrays, and 14 of the integrons harbored a single gene cassette. All but two harbored the bla $a_{\mathrm{IMP}}$ gene cassette in the first of the array (70.0\%) or in the second of the array $(22.9 \%)$. Less frequently, the bla $a_{\mathrm{GIM}-1}$ gene cassette was identified in six class 1 integrons of five different arrays all in the first of the array, and three bla $a_{\mathrm{GES}-5}$ cassette-associated and one of each of the $b l a_{\mathrm{GES}-8}, b l a_{\mathrm{GES}-9}$, and $b l a_{\mathrm{GES}-15}$ cassetteassociated class 1 integrons were identified.

\section{Mobilized Class 1 Integrons}

Basically, class 1 integrons are immobile per se, and a set of functional transposition modules is needed for transposition (Martinez et al., 2012). The Tn402 family transposon Tn5090 is a good example of a functional transposon giving mobility to a class 1 integron (Figure 9; Radstrom et al., 1994). The Tn402 family transposon is a Mu-related transposon that has been identified in the broad-host IncP plasmid R751 conferring trimethoprim resistance (Jobanputra and Datta, 1974; Shapiro and Sporn, 1977). The transposon family has two modules: a transposition module composed of the transposase TniA, the ATP-binding protein $\mathrm{TniB}$, the transposition auxiliary protein TniQ-resolution site res, the serine resolvase TniC, and a class 1 integron carrying antimicrobial resistance gene cassettes. Transposition of the Tn 402 family transposon involves a TniABQ-dependent cointegrate formation and a site-specific serine resolvase-dependent resolution (Radstrom et al., 1994). The transposon has 25-bp inverted repeats, and the integration generates 5-bp DRs. The transposon targets the res site of Tn21 subfamily transposons as well as resolution sites found on plasmids (Minakhina et al., 1999). The Tn21-like Tn1403, Tn6060, Tn6162, and Tn6249, which nest inside the Tn402-like, carry a class 1 integron possessing the bla $a_{\mathrm{VIM}-1}$ gene cassette (Di Pilato et al., 2015).

In the transposon repository database (Tansirichaiya et al., 2019), a total of 20 transposons carried the gene encoding carbapenemases (Supplementary Table 1), and of those, 19 transposons are associated with class 1 integrons harboring the bla $_{\mathrm{VIM}}(n=9), b l a_{\mathrm{IMP}}(n=6), b l a_{\mathrm{GES}}(n=2), b l a_{\mathrm{SIM}}(n=1)$, and bla $a_{\text {DIM }}(n=1)$ gene cassettes. The 207 complete $P$. aeruginosa genomes from the Genome Database included a total of 29 chromosomal class 1 integrons with a carbapenemase-encoding gene cassette. Among those, 20 integrons included a part or the entire set of the TniABQR transposition module of the Tn402-like.

\section{Resistance Islands Harboring the Carbapenemase-Encoding Genes}

Genomic islands carrying many foreign genes are useful for adaptation by providing multiple fitness-associated elements to $P$. aeruginosa in a single event of horizontal gene transfer (Kung et al., 2010). Genomic islands are often free to move in and out of the chromosome, and pKLC102, a 100-kb plasmid identified in $P$. aeruginosa $\mathrm{C}$ strain, is an example of this (Klockgether et al., 2004). The plasmid pKLC102 was found simultaneously in the 
$\operatorname{Tn} 5090$

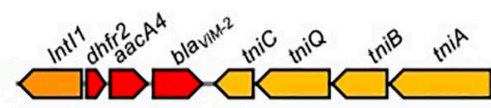

[AM993098]

$\operatorname{Tn} 1403$

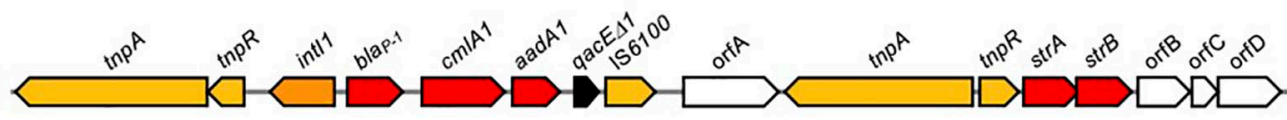

[AF313472]

$\operatorname{Tn} 21$

[AF071413]

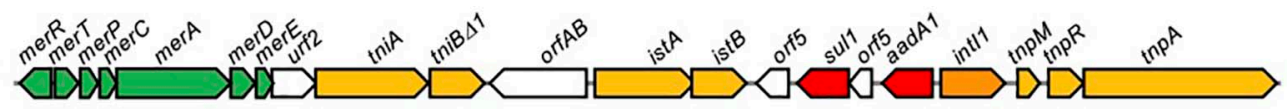

FIGURE 9 | Transposons giving mobility to integrons. Transposons are indicated in scale with the component. The accession number of each sequence is indicated in brackets. Arrows indicate open reading frames with filled colors that differ by function: yellow, transposition; orange, class 1 integrase; red, antimicrobial resistance; green, heavy metal resistance (Radstrom et al., 1994; Minakhina et al., 1999; Shi et al., 2018).

\section{A Group 1 resistance island}

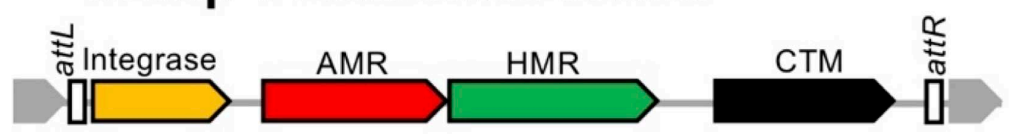

B

Group 2 resistance island

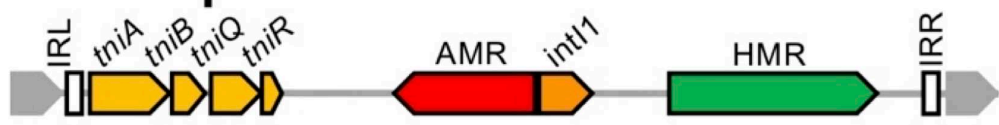

C

Ungroupable resistance island

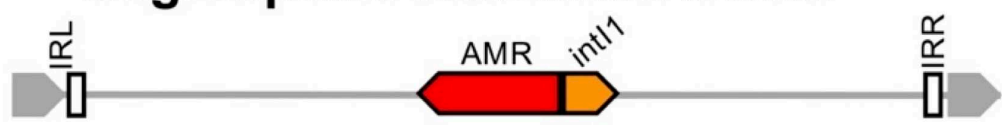

FIGURE 10 | Schematic presentation of the structure of genomic islands belonging to the three groups. The schematic structure is presented for the three groups of genomic islands: (A) Group 1 resistance islands equipping the tyrosine-based integrase gene at the 5' terminal and the conjugative transfer machinery gene cluster at the 3' terminus, (B) Group 2 resistance islands carrying a transposition module of a whole or a partial TniABQR component, (C) and the others. The genes are indicated with open arrows and colored based on function: genes for integration and recombination of the genomic island are in yellow, genes for antimicrobial resistance (AMR) are in red, genes for heavy metal resistance (HMR) are in green, the int/1 gene is in orange, conjugative transfer module mostly composed of the type 4 pili assembly genes is in black, and the core gene is in gray. The open box indicates inverted repeats (IRs) left and right, named the attL and attR loci for integration conjugative elements.

chromosome as a genomic island being integrated into the $3^{\prime}$ end of the tRNA ${ }^{L y s}$ gene in favor of an att site.

Genomic islands are typically inserted at the $3^{\prime}$ end of a transfer RNA (tRNA) gene; however, they are also targeted elsewhere in the chromosome (Klockgether et al., 2011). Genomic islands are easily differentiated from the core genome by their atypical $\mathrm{G}+\mathrm{C}$ contents, differing from the typical $P$. aeruginosa $\mathrm{G}+\mathrm{C}$ content of $65-67 \%$ and atypical oligonucleotide usage. Genomic islands typically harbor the genes for factors involved in mobility, such as integrases, transposases, ISs, and other components responsible for biological processes. Genomic islands are categorized accordingly to their main characteristics determined by the gene content, such as pathogenicity, symbiosis, metabolic, fitness, or drug resistance. Thus far, 25 genomic islands have been identified: two $P$. aeruginosa pathogenic islands, PAPI1 and PAPI-2; 17 P. aeruginosa genomic islands, PAGI-1 to PAGI-17; five Liverpool epidemic strain genomic islands, LESGI1 to LESGI-5; and a plasmid-origin genomic island, pKLC102. As an effort to group the genomic islands, Kung et al. (2010) suggested two families of genomic islands by conserved function 
and synteny of the backbone genes, and Klockgether et al. (2011) proposed that any known genomic islands originated from an ancestry based on conserved orthologs. However, no scheme is publicly endorsed.

Genomic islands carrying the antimicrobial resistance genes, so-called resistance islands, specifically provide a great advantage for survival to bacterial hosts in clinical settings. Among the 25 genomic islands, only three-PAGI-13 in P. aeruginosa ST277 (Silveira et al., 2014) and PAGI-15 in ST244 and PAGI-16 in ST235, respectively (Hong et al., 2016) - were resistance islands carrying antimicrobial resistance determinants, and only two, PAGI-15 (bla $\left.a_{\mathrm{GES}-24}\right)$ and PAGI-16 (bla $a_{\mathrm{IMP}-6}$, or $\left.b l a_{\mathrm{IMP}-10}\right)$, harbored a carbapenemase-encoding gene (Table 1; Hong et al., 2016). One unnamed PAGI-2-like island in P. aeruginosa ST235 carrying the bla $a_{\mathrm{GES}-5}$ gene has also been reported (Abril et al., 2019).

In addition, the PA143/97 genomic island, which was manufactured to include the Tn6249 carrying two class 1 integrons harboring the bla $a_{\mathrm{VIM}-2}$ gene cassette, was reported (Martinez et al., 2012; Di Pilato et al., 2015).

Pseudomonas aeruginosa is able to obtain multidrug resistance at once through resistance islands. Since this review focuses on carbapenem resistance in $P$. aeruginosa, the exploration is restricted to genomic islands harboring carbapenemaseencoding genes.

Among the 207 complete genomes of $P$. aeruginosa extracted from the Genome Database, a total of 38 chromosomes harbor resistance islands carrying the carbapenemase-encoding gene, and eight of those carry two resistance islands. In total, 45 resistance islands, sized between 8,858 and $117,103 \mathrm{bp}$, were analyzed. The $\mathrm{G}+\mathrm{C}$ contents varied from 55.5 to $65.5 \%$, which were lower than those of the chromosomes, which were from 65 to $67 \%$, and the integration sites varied.

The 45 resistance islands carrying the carbapenemaseencoding gene were classified into three groups by the transposition module (Table 2). Group 1 resistance islands furnish the tyrosine-based integrase gene at the 5 'terminal and the conjugative transfer machinery gene cluster at the $3^{\prime}$ terminus (Figure 10). Group 1 can be further grouped into two subgroups: group 1a, with a core structure of $\mathrm{ICE}_{\mathrm{Tn} 4371}$ mostly targeting OprD of OccD4/OpdT tyrosine or adenylate cyclase ExoY, and group $1 \mathrm{~b}$, which resembles the known multidrugresistant genomic islands PAGI-13, PAGI-15, and PAGI-16 targeting tRNA $\mathrm{Gly}_{\text {. }}$. Resistance islands belonging to group 1a had G+C contents between 64.5 and $65.1 \%$, and the size was $44-$ $74 \mathrm{kbp}$. The $b a_{\mathrm{SPM}-1}$ and $b a_{\mathrm{NDM}-1}$ genes carried by the group 1a resistance islands were all associated with IS91-like ISCRs composing unit transposons, and neither the other antimicrobial resistance determinants nor the heavy metal resistance-associated genes were identified in the resistance island. Meanwhile, the $\mathrm{G}+\mathrm{C}$ contents of group $1 \mathrm{~b}$ ranged between 60.5 and $64.2 \%$, and the size ranged from 37 to $117 \mathrm{kbp}$. The upper cluster of group $1 \mathrm{~b}$, including four genomic islands (Table 2), targeted tRNA $\mathrm{Gly}_{\mathrm{y}}$ at the locus PA0714 of the genome of $P$. aeruginosa PAO1 (NCBI RefSeq, NC_002516.2). Characteristically, the genomic islands belonging to the cluster always possess the mercury resistance gene cluster, which is likely derived from Tn501,

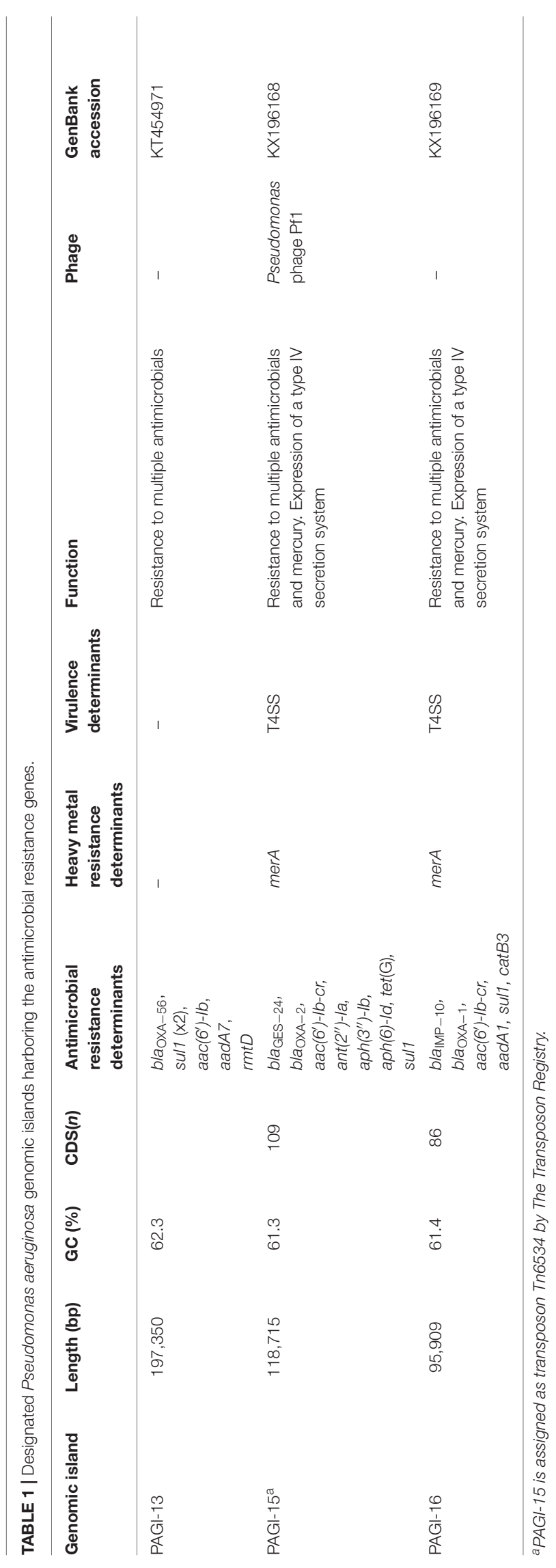


TABLE 2 | Resistance islands carrying the carbapenemase-encoding gene in Pseudomonas aeruginosa.

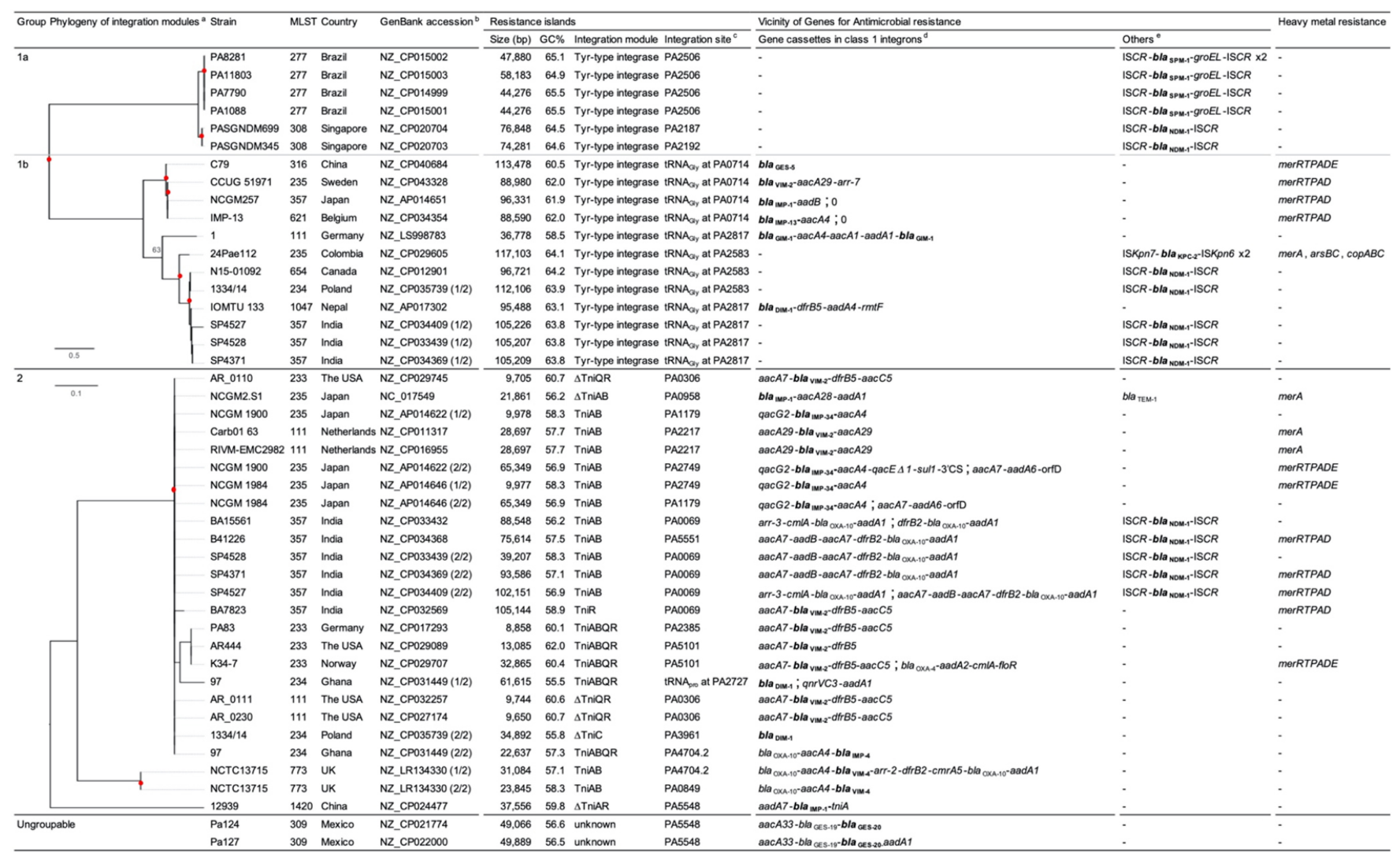

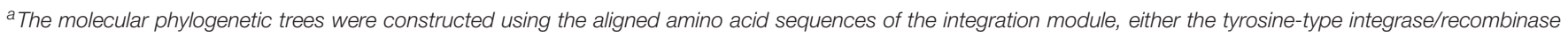

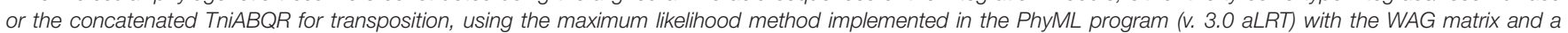

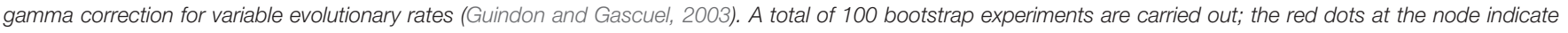
perfect robustness.

b If the chromosome includes two genomic islands, each case is indicated with numbers 1/2 and 2/2 in brackets following the GenBank accession number.

cIntegration sites are indicated using the locus tag of the genome of P. aeruginosa PAO1 (NCBI RefSeq, NC_002516.2).

"InO is indicated with "O."

${ }^{e}$ Antimicrobial resistance genes located in a class 1 integron and transposons are indicated, and the genes encoding carbapenemase are in boldface.

and the carbapenemase-encoding genes are carried by class 1 integrons as a gene cassette. The eight genomic islands belonging to the next cluster of subgroup $1 \mathrm{~b}$ targeted $\mathrm{tRNA}_{\mathrm{Gly}}$ either at the locus PA2583 or PA2817 of the PAO1 genome. A quarter of the genomic islands possess a class 1 integron, and the acquisition of the carbapenemase-encoding gene is mostly due to ISCR elements. Pieces of the heavy metal gene cluster have been observed.

The group 2 resistance islands contain a transposition module composed of a whole or a partial TniABQR component. The resistance islands had obviously lower $\mathrm{G}+\mathrm{C}$ contents, between 55.5 and $62.0 \%$, and the sizes were diverse, from 8.8 to $105 \mathrm{kbp}$. The composition of the resistance islands in group 2 corresponds to that of the Proteus genomic island PGI-1 (Mac Aogain et al., 2016). The resistance islands are constructed through the accumulated assemblage on a Tn402 backbone. Such an assemblage of transposons is commonly observed in the AbaRtype resistance islands in A. baumannii, which evolved from the Tn6019 backbone (Krizova et al., 2011).

In the case of the remaining two resistance islands, categorization is unavailable since only two cases of possible clonal relations are available from the GenBank database. Neither a specific tyrosine-based recombinase nor a transposition component has been identified in the resistance islands; however, they are flanked by 20 -bp inverted repeats.

\section{CONCLUSION}

Carbapenems represent a valuable therapeutic option for patients with infections caused by multidrug-resistant $P$. aeruginosa. It is ironic that carbapenem resistance, especially that conferred by carbapenemase production, is closely related to multidrug resistance, highlighting the role of modular mobile units carrying multiple antimicrobial resistance determinants. The molecular epidemiology of antimicrobial resistance has been studied by traditional methodologies based on PCR and Sanger sequencing to identify the resistance genes and to distinguish the fundamental mobile genetic elements carrying the gene, i.e., gene cassettes of integrons, transposons, and plasmids. The present era of massive next-generation sequencing, mostly the long-read sequencing, allows resolving a wide range of complex genome regions, such as modular mobile units associated with genes 
for antimicrobial resistance, also known as resistance islands. Such an extensive analysis has been carried out for limited numbers of the $P$. aeruginosa genome mostly for the genomic islands unrelated to antimicrobial resistance determinants. Among the plenty genomic islands in the genome of $P$. aeruginosa, resistance islands have a meaning beyond genome plasticity. Such a modular mobile unit harboring antimicrobial resistance determinants is able to disseminate by itself and capture an alien gene for resistance, which means the resistance islands and high-risk clones are the $\mathrm{A}$ to $\mathrm{Z}$ of acquisition of multidrug resistance. Our trial to classify $P$. aeruginosa resistance islands needs improvement with more cases for resistance islands.

The global spread of the carbapenem-resistant $P$. aeruginosa is one of the major global public health challenges, and the epidemiological scenario is often associated with the circulation of carbapenemase-encoding genes linked with (i) the endemic carbapenemase gene and (ii) the carbapenem usage in clinical settings. The KPC-producing $P$. aeruginosa in KPC-endemic United States, the SPM-producing P. aeruginosa in SPMendemic Brazil, and the NDM-producing P. aeruginosa in NDMendemic India exemplify well the first linkage. The second linkage is illustrated through the dominance of IMP-6-producing $P$. aeruginosa in South Korea, in which meropenem usage is approximately twice more in clinical settings than that of imipenem. Since IMP-6 has greater hydrolyzing activity to meropenem than to imipenem compared to the other subtypes of IMP enzymes, producing the IMP-6 subtype is favorable to the bacterial host. It emphasizes that the carbapenemaseproducing organisms should be controlled regardless of the bacterial host, and control includes both surveillance study and antimicrobial stewardship. Needless to say, more attention is needed to be paid to the emergence and spread of the highrisk $P$. aeruginosa clones, together with their enzymatic/nonenzymatic carbapenem resistance. Though continuing efforts are being made to develop the beta-lactamase inhibitors in order to preserve the efficacy of beta-lactam drugs including carbapenems, it is fruitful just for the serine beta-lactamases. Development of the inhibitors for MBLs, which are frequently produced by $P$. aeruginosa, is eager to be accelerated.

\section{REFERENCES}

Abril, D., Marquez-Ortiz, R. A., Castro-Cardozo, B., Moncayo-Ortiz, J. I., Olarte Escobar, N. M., Corredor Rozo, Z. L., et al. (2019). Genome plasticity favours double chromosomal Tn4401b-blaKPC-2 transposon insertion in the Pseudomonas aeruginosa ST235 clone. BMC Microbiol. 19:45. doi: 10.1186/ s12866-019-1418-6

Adam, M. A., and Elhag, W. I. (2018). Prevalence of metallo-beta-lactamase acquired genes among carbapenems susceptible and resistant Gram-negative clinical isolates using multiplex PCR, Khartoum hospitals, Khartoum Sudan. BMC Infect. Dis. 18:668. doi: 10.1186/s12879-018-3581-z

Akpaka, P. E., Swanston, W. H., Ihemere, H. N., Correa, A., Torres, J. A., Tafur, J. D., et al. (2009). Emergence of KPC-producing Pseudomonas aeruginosa in Trinidad and Tobago. J. Clin. Microbiol. 47, 2670-2671. doi: 10.1128/jcm. 00362-09

Al-Agamy, M. H., Shibl, A. M., Tawfik, A. F., and Radwan, H. H. (2009). High prevalence of metallo-beta-lactamase-producing Pseudomonas aeruginosa from Saudi Arabia. J. Chemother. 21, 461-462.
Despite the efforts to control the spread of carbapenemresistant $P$. aeruginosa, a conclusive solution to the issue is still far from being accomplished. Surveillance study for the drugresistant pathogen is essential and global collaboration using harmonized methods is important for a practical comparison of the outputs. In addition, to fight against the drug-resistant pathogen, we need to understand how the pathogens acquire resistance determinants. Taking the advantages of up-to-date techniques, assessment of the bacterial genome should be carried out, not only for the mobile genetic elements carrying a carbapenemase-encoding gene but also for the genomic islands. Furthermore, through the technique, the mobile genetic elements should be investigated extensively, and it would allow a comprehensive grasp of the dissemination of drug resistance.

\section{AUTHOR CONTRIBUTIONS}

SJ conceived and supervised the study, performed the data evaluation and confirmation, and finalized and edited the manuscript. E-JY carried out the analysis and data validation, and drafted the manuscript. Both authors contributed to the article and approved the submitted version.

\section{FUNDING}

This work was supported by a fund (NRF-2018R1C1B6002674) from the National Research Foundation of Korea. The funders had no role in the design of the study, in the collection, analysis, or interpretation of data, in the writing of the manuscript, or in the decision to publish to the results.

\section{SUPPLEMENTARY MATERIAL}

The Supplementary Material for this article can be found online at: https://www.frontiersin.org/articles/10.3389/fmicb. 2021.614058/full\#supplementary-material

Angus, B. L., Carey, A. M., Caron, D. A., Kropinski, A. M., and Hancock, R. E. (1982). Outer membrane permeability in Pseudomonas aeruginosa: comparison of a wild-type with an antibiotic-supersusceptible mutant. Antimicrob. Agents Chemother. 21, 299-309. doi: 10.1128/aac.21.2.299

Arakawa, Y., Murakami, M., Suzuki, K., Ito, H., Wacharotayankun, R., Ohsuka, S., et al. (1995). A novel integron-like element carrying the metallo-beta-lactamase gene blaIMP. Antimicrob. Agents Chemother. 39, 1612-1615. doi: 10.1128/aac. 39.7.1612

Araujo, B. F., Royer, S., Campos, P. A., Ferreira, M. L., Goncalves, I. R., Machado, L. G., et al. (2018). Insights into a novel Tn4401 deletion (Tn4401i) in a multidrug-resistant Klebsiella pneumoniae clinical strain belonging to the highrisk clonal group 258 producing KPC-2. Int. J. Antimicrob. Agents 52, 525-527. doi: 10.1016/j.ijantimicag.2018.08.011

Azim, A., Dwivedi, M., Rao, P. B., Baronia, A. K., Singh, R. K., Prasad, K. N., et al. (2010). Epidemiology of bacterial colonization at intensive care unit admission with emphasis on extended-spectrum beta-lactamase- and metallo-betalactamase-producing Gram-negative bacteria-an Indian experience. J. Med. Microbiol. 59, 955-960. doi: 10.1099/jmm.0.018085-0 
Bahar, G., Mazzariol, A., Koncan, R., Mert, A., Fontana, R., Rossolini, G. M., et al. (2004). Detection of VIM-5 metallo-beta-lactamase in a Pseudomonas aeruginosa clinical isolate from Turkey. J. Antimicrob. Chemother. 54, 282-283. doi: $10.1093 / \mathrm{jac} / \mathrm{dkh} 321$

Bebrone, C., Bogaerts, P., Delbruck, H., Bennink, S., Kupper, M. B., Rezende De Castro, R., et al. (2013). GES-18, a new carbapenem-hydrolyzing GES-type beta-lactamase from Pseudomonas aeruginosa that contains Ile80 and Ser170 residues. Antimicrob. Agents Chemother. 57, 396-401. doi: 10.1128/aac.017 84-12

Bonnin, R. A., Bogaerts, P., Girlich, D., Huang, T. D., Dortet, L., Glupczynski, Y., et al. (2018). Molecular characterization of OXA-198 carbapenemaseproducing Pseudomonas aeruginosa clinical isolates. Antimicrob. Agents Chemother. 62, e02496-17.

Bontron, S., Nordmann, P., and Poirel, L. (2016). Transposition of Tn125 encoding the NDM-1 carbapenemase in Acinetobacter baumannii. Antimicrob. Agents Chemother. 60, 7245-7251.

Borah, V. V., Saikia, K. K., and Hazarika, N. K. (2016). First report on the detection of OXA-48 beta-lactamase gene in Escherichia coli and Pseudomonas aeruginosa co-infection isolated from a patient in a tertiary care hospital in Assam. Indian J. Med. Microbiol. 34, 252-253. doi: 10.4103/0255-0857.176842

Bosnjak, Z., Bedenic, B., Mazzariol, A., Jarza-Davila, N., Suto, S., and Kalenic, S. (2010). VIM-2 beta-lactamase in Pseudomonas aeruginosa isolates from Zagreb, Croatia. Scand. J. Infect. Dis. 42, 193-197. doi: 10.3109/003655409034 26582

Botelho, J., Grosso, F., Quinteira, S., Brilhante, M., Ramos, H., and Peixe, L. (2018). Two decades of blaVIM-2-producing Pseudomonas aeruginosa dissemination: an interplay between mobile genetic elements and successful clones. J. Antimicrob. Chemother. 73, 873-882. doi: 10.1093/jac/dkx517

Boyd, D. A., Lisboa, L. F., Rennie, R., Zhanel, G. G., Dingle, T. C., and Mulvey, M. R. (2019). Identification of a novel metallo-beta-lactamase, CAM-1, in clinical Pseudomonas aeruginosa isolates from Canada. J. Antimicrob. Chemother. 74, 1563-1567. doi: 10.1093/jac/dkz066

Bryant, K. A., Van Schooneveld, T. C., Thapa, I., Bastola, D., Williams, L. O., Safranek, T. J., et al. (2013). KPC-4 is encoded within a truncated Tn4401 in an IncL/M plasmid, pNE1280, isolated from Enterobacter cloacae and Serratia marcescens. Antimicrob. Agents Chemother. 57, 37-41. doi: 10.1128/aac. 01062-12

Cai, S., Chen, Y., Song, D., Kong, J., Wu, Y., and Lu, H. (2016). Study on the resistance mechanism via outer membrane protein OprD2 and metal betalactamase expression in the cell wall of Pseudomonas aeruginosa. Exp. Ther. Med. 12, 2869-2872. doi: 10.3892/etm.2016.3690

Cambray, G., Guerout, A. M., and Mazel, D. (2010). Integrons. Annu. Rev. Genet. $44,141-166$.

Carattoli, A., Fortini, D., Galetti, R., Garcia-Fernandez, A., Nardi, G., Orazi, D., et al. (2013). Isolation of NDM-1-producing Pseudomonas aeruginosa sequence type ST235 from a stem cell transplant patient in Italy, May 2013. Euro Surveill. $18,20633$.

Castanheira, M., Bell, J. M., Turnidge, J. D., Mathai, D., and Jones, R. N. (2009). Carbapenem resistance among Pseudomonas aeruginosa strains from India: evidence for nationwide endemicity of multiple metallo-beta-lactamase clones (VIM-2, -5, -6, and -11 and the newly characterized VIM-18). Antimicrob. Agents Chemother. 53, 1225-1227. doi: 10.1128/aac.01011-08

Castanheira, M., Costello, S. E., Woosley, L. N., Deshpande, L. M., Davies, T. A., and Jones, R. N. (2014a). Evaluation of clonality and carbapenem resistance mechanisms among Acinetobacter baumannii-Acinetobacter calcoaceticus complex and Enterobacteriaceae isolates collected in European and Mediterranean countries and detection of two novel beta-lactamases, GES-22 and VIM-35. Antimicrob. Agents Chemother. 58, 7358-7366. doi: $10.1128 /$ aac.03930-14

Castanheira, M., Deshpande, L. M., Costello, A., Davies, T. A., and Jones, R. N. (2014b). Epidemiology and carbapenem resistance mechanisms of carbapenem-non-susceptible Pseudomonas aeruginosa collected during 200911 in 14 European and Mediterranean countries. J. Antimicrob. Chemother. 69, 1804-1814. doi: 10.1093/jac/dku048

Castanheira, M., Toleman, M. A., Jones, R. N., Schmidt, F. J., and Walsh, T. R. (2004). Molecular characterization of a beta-lactamase gene, blaGIM1, encoding a new subclass of metallo-beta-lactamase. Antimicrob. Agents Chemother. 48, 4654-4661. doi: 10.1128/aac.48.12.4654-4661.2004
Chalhoub, H., Saenz, Y., Rodriguez-Villalobos, H., Denis, O., Kahl, B. C., Tulkens, P. M., et al. (2016). High-level resistance to meropenem in clinical isolates of Pseudomonas aeruginosa in the absence of carbapenemases: role of active efflux and porin alterations. Int. J. Antimicrob. Agents 48, 740-743. doi: 10.1016/j. ijantimicag.2016.09.012

Chaves, L., Tomich, L. M., Salomao, M., Leite, G. C., Ramos, J., Martins, R. R., et al. (2017). High mortality of bloodstream infection outbreak caused by carbapenem-resistant P. aeruginosa producing SPM-1 in a bone marrow transplant unit. J. Med. Microbiol. 66, 1722-1729. doi: 10.1099/jmm.0.000631

Chen, Y., Sun, M., Wang, M., Lu, Y., and Yan, Z. (2014). Dissemination of IMP6-producing Pseudomonas aeruginosa ST244 in multiple cities in China. Eur. J. Clin. Microbiol. Infect. Dis. 33, 1181-1187. doi: 10.1007/s10096-014-2063-5

Cheruvanky, A., Stoesser, N., Sheppard, A. E., Crook, D. W., Hoffman, P. S., Weddle, E., et al. (2017). Enhanced Klebsiella pneumoniae carbapenemase expression from a novel Tn4401 deletion. Antimicrob. Agents Chemother. 61, e00025-17. doi: 10.1128/AAC.00025-17

Cholley, P., Ka, R., Guyeux, C., Thouverez, M., Guessennd, N., Ghebremedhin, B., et al. (2014). Population structure of clinical Pseudomonas aeruginosa from West and Central African countries. PLoS One 9:e107008. doi: 10.1371/journal. pone. 0107008

Collis, C. M., Grammaticopoulos, G., Briton, J., Stokes, H. W., and Hall, R. M. (1993). Site-specific insertion of gene cassettes into integrons. Mol. Microbiol. 9, 41-52. doi: 10.1111/j.1365-2958.1993.tb01667.x

Collis, C. M., and Hall, R. M. (1992). Gene cassettes from the insert region of integrons are excised as covalently closed circles. Mol. Microbiol. 6, 2875-2885. doi: 10.1111/j.1365-2958.1992.tb01467.x

Correa, A., Del Campo, R., Perenguez, M., Blanco, V. M., Rodriguez-Banos, M., Perez, F., et al. (2015). Dissemination of high-risk clones of extensively drugresistant Pseudomonas aeruginosa in colombia. Antimicrob. Agents Chemother. 59, 2421-2425. doi: 10.1128/aac.03926-14

Coyne, S., Guigon, G., Courvalin, P., and Perichon, B. (2010). Screening and quantification of the expression of antibiotic resistance genes in Acinetobacter baumannii with a microarray. Antimicrob. Agents Chemother. 54, 333-340. doi: 10.1128/aac.01037-09

Crespo, M. P., Woodford, N., Sinclair, A., Kaufmann, M. E., Turton, J., Glover, J., et al. (2004). Outbreak of carbapenem-resistant Pseudomonas aeruginosa producing VIM-8, a novel metallo-beta-lactamase, in a tertiary care center in Cali, Colombia. J. Clin. Microbiol. 42, 5094-5101. doi: 10.1128/jcm.42.11.50945101.2004

Cuzon, G., Naas, T., and Nordmann, P. (2011). Functional characterization of Tn4401, a Tn3-based transposon involved in blaKPC gene mobilization. Antimicrob. Agents Chemother. 55, 5370-5373. doi: 10.1128/aac.05202-11

Dai, X., Zhou, D., Xiong, W., Feng, J., Luo, W., Luo, G., et al. (2016). The IncP-6 plasmid p10265-KPC from Pseudomonas aeruginosa carries a novel deltaISEc33-associated blaKPC-2 gene cluster. Front. Microbiol. 7:310. doi: 10. 3389/fmicb.2016.00310

de Oliveira Santos, I. C., Pereira De Andrade, N. F., Da Conceicao Neto, O. C., Da Costa, B. S., De Andrade Marques, E., Rocha-De-Souza, C. M., et al. (2019). Epidemiology and antibiotic resistance trends in clinical isolates of Pseudomonas aeruginosa from Rio de janeiro - Brazil: Importance of mutational mechanisms over the years (1995-2015). Infect. Genet. Evol. 73, 411-415. doi: 10.1016/j.meegid.2019.05.015

Del Barrio-Tofino, E., Lopez-Causape, C., and Oliver, A. (2020). Pseudomonas aeruginosa epidemic high-risk clones and their association with horizontallyacquired beta-lactamases: 2020 update. Int. J. Antimicrob. Agents 56, 106196. doi: 10.1016/j.ijantimicag.2020.106196

del Pilar Garcillan-Barcia, M., Bernales, I., Mendiola, M. V., and De La Cruz, F. (2001). Single-stranded DNA intermediates in IS91 rolling-circle transposition. Mol. Microbiol. 39, 494-501. doi: 10.1046/j.1365-2958.2001.02261.x

Delgado-Valverde, M., Conejo, M. D. C., Serrano, L., Fernandez-Cuenca, F., and Pascual, A. (2020). Activity of cefiderocol against high-risk clones of multidrugresistant Enterobacterales, Acinetobacter baumannii, Pseudomonas aeruginosa and Stenotrophomonas maltophilia. J. Antimicrob. Chemother. 75, 1840-1849. doi: 10.1093/jac/dkaa117

Deplano, A., Rodriguez-Villalobos, H., Glupczynski, Y., Bogaerts, P., Allemeersch, D., Grimmelprez, A., et al. (2007). Emergence and dissemination of multidrug resistant clones of Pseudomonas aeruginosa producing VIM-2 metallo-betalactamase in Belgium. Euro Surveill. 12, E070118070112. 
Di Pilato, V., Antonelli, A., Giani, T., Henrici De Angelis, L., Rossolini, G. M., and Pollini, S. (2019). Identification of a novel plasmid lineage associated with the dissemination of metallo-beta-lactamase genes among Pseudomonas. Front. Microbiol. 10:1504. doi: 10.3389/fmicb.2019.01504

Di Pilato, V., Pollini, S., and Rossolini, G. M. (2015). Tn6249, a new Tn6162 transposon derivative carrying a double-integron platform and involved with acquisition of the blaVIM-1 metallo-beta-lactamase gene in Pseudomonas aeruginosa. Antimicrob. Agents Chemother. 59, 1583-1587. doi: 10.1128/aac. 04047-14

Diaz-Aroca, E., Mendiola, M. V., Zabala, J. C., and De La Cruz, F. (1987). Transposition of IS91 does not generate a target duplication. J. Bacteriol. 169, 442-443. doi: 10.1128/jb.169.1.442-443.1987

Docquier, J. D., Lamotte-Brasseur, J., Galleni, M., Amicosante, G., Frere, J. M., and Rossolini, G. M. (2003). On functional and structural heterogeneity of VIM-type metallo-beta-lactamases. J. Antimicrob. Chemother. 51, 257-266. doi: $10.1093 / \mathrm{jac} / \mathrm{dkg} 067$

Dortet, L., Flonta, M., Boudehen, Y. M., Creton, E., Bernabeu, S., Vogel, A., et al. (2015). Dissemination of carbapenemase-producing Enterobacteriaceae and Pseudomonas aeruginosa in Romania. Antimicrob. Agents Chemother. 59, 7100-7103. doi: 10.1128/aac.01512-15

Dortet, L., Poirel, L., and Nordmann, P. (2014). Worldwide dissemination of the NDM-type carbapenemases in Gram-negative bacteria. Biomed. Res. Int. 2014, 249856.

Edelstein, M. V., Skleenova, E. N., Shevchenko, O. V., D’souza, J. W., Tapalski, D. V., Azizov, I. S., et al. (2013). Spread of extensively resistant VIM-2positive ST235 Pseudomonas aeruginosa in Belarus, Kazakhstan, and Russia: a longitudinal epidemiological and clinical study. Lancet Infect. Dis. 13, 867-876. doi: 10.1016/s1473-3099(13)70168-3

El Solh, A. A., and Alhajhusain, A. (2009). Update on the treatment of Pseudomonas aeruginosa pneumonia. J. Antimicrob. Chemother. 64, 229-238. doi: 10.1093/ $\mathrm{jac} / \mathrm{dkp} 201$

Elias, J., Schoen, C., Heinze, G., Valenza, G., Gerharz, E., Gerharz, H., et al. (2010). Nosocomial outbreak of VIM-2 metallo-beta-lactamase-producing Pseudomonas aeruginosa associated with retrograde urography. Clin. Microbiol. Infect. 16, 1494-1500. doi: 10.1111/j.1469-0691.2010.03146.x

Falahat, S., Shojapour, M., and Sadeghi, A. (2016). Detection of KPC carbapenemase in Pseudomonas aeruginosa isolated from clinical samples using modified hodge test and boronic acid phenotypic methods and their comparison with the polymerase chain reaction, Jundishapur. J. Microbiol. 9, e27249.

Fan, X., Wu, Y., Xiao, M., Xu, Z. P., Kudinha, T., Bazaj, A., et al. (2016). Diverse genetic background of multidrug-resistant Pseudomonas aeruginosa from mainland China, and emergence of an extensively drug-resistant ST292 clone in kunming. Sci. Rep. 6, 26522.

Farra, A., Islam, S., Stralfors, A., Sorberg, M., and Wretlind, B. (2008). Role of outer membrane protein OprD and penicillin-binding proteins in resistance of Pseudomonas aeruginosa to imipenem and meropenem. Int. J. Antimicrob. Agents 31, 427-433. doi: 10.1016/j.ijantimicag.2007.12.016

Feng, W., Sun, F., Wang, Q., Xiong, W., Qiu, X., Dai, X., et al. (2017). Epidemiology and resistance characteristics of Pseudomonas aeruginosa isolates from the respiratory department of a hospital in China. J. Glob. Antimicrob. Resist. 8, 142-147. doi: 10.1016/j.jgar.2016.11.012

Findlay, J., Hopkins, K. L., Loy, R., Doumith, M., Meunier, D., Hill, R., et al. (2017). OXA-48-like carbapenemases in the UK: an analysis of isolates and cases from 2007 to 2014. J. Antimicrob. Chemother. 72, 1340-1349. doi: 10.1093/jac/ $\mathrm{dkx} 012$

Fournier, D., Jeannot, K., Robert-Nicoud, M., Muller, E., Cholley, P., Van Der MeeMarquet, N., et al. (2012). Spread of the blaIMP-13 gene in French Pseudomonas aeruginosa through sequence types ST621, ST308 and ST111. Int. J. Antimicrob. Agents 40, 571-573. doi: 10.1016/j.ijantimicag.2012.08.006

Frase, H., Shi, Q., Testero, S. A., Mobashery, S., and Vakulenko, S. B. (2009). Mechanistic basis for the emergence of catalytic competence against carbapenem antibiotics by the GES family of beta-lactamases. J. Biol. Chem. 284, 29509-29513. doi: 10.1074/jbc.m109.011262

Frere, J. M., Galleni, M., Bush, K., and Dideberg, O. (2005). Is it necessary to change the classification of beta-lactamases? J. Antimicrob. Chemother. 55, 1051-1053. doi: 10.1093/jac/dki155
Galetti, R., Andrade, L. N., Chandler, M., Varani Ade, M., and Darini, A. L. (2016). New small plasmid harboring blaKPC-2 in Pseudomonas aeruginosa. Antimicrob. Agents Chemother. 60, 3211-3214. doi: 10.1128/aac.00247-16

Garcia-Castillo, M., Del Campo, R., Morosini, M. I., Riera, E., Cabot, G., Willems, R., et al. (2011). Wide dispersion of ST175 clone despite high genetic diversity of carbapenem-nonsusceptible Pseudomonas aeruginosa clinical strains in 16 Spanish hospitals. J. Clin. Microbiol. 49, 2905-2910. doi: 10.1128/jcm.00753-11

Garza-Ramos, U., Morfin-Otero, R., Sader, H. S., Jones, R. N., Hernandez, E., Rodriguez-Noriega, E., et al. (2008). Metallo-beta-lactamase gene blaIMP-15 in a class 1 integron, In95, from Pseudomonas aeruginosa clinical isolates from a hospital in Mexico. Antimicrob. Agents Chemother. 52, 2943-2946. doi: 10. 1128/aac.00679-07

Ge, C., Wei, Z., Jiang, Y., Shen, P., Yu, Y., and Li, L. (2011). Identification of KPC-2-producing Pseudomonas aeruginosa isolates in China. J. Antimicrob. Chemother. 66, 1184-1186. doi: 10.1093/jac/dkr060

Giani, T., Arena, F., Pollini, S., Di Pilato, V., D’andrea, M. M., Henrici De Angelis, L., et al. (2018). Italian nationwide survey on Pseudomonas aeruginosa from invasive infections: activity of ceftolozane/tazobactam and comparators, and molecular epidemiology of carbapenemase producers. J. Antimicrob. Chemother. 73, 664-671. doi: 10.1093/jac/dkx453

Gibb, A. P., Tribuddharat, C., Moore, R. A., Louie, T. J., Krulicki, W., Livermore, D. M., et al. (2002). Nosocomial outbreak of carbapenem-resistant Pseudomonas aeruginosa with a new blaIMP allele, blaIMP-7. Antimicrob. Agents Chemother. 46, 255-258. doi: 10.1128/aac.46.1.255-258.2002

Golemi, D., Maveyraud, L., Vakulenko, S., Samama, J. P., and Mobashery, S. (2001). Critical involvement of a carbamylated lysine in catalytic function of class D beta-lactamases. Proc. Natl. Acad. Sci. U.S.A. 98, 14280-14285. doi: 10.1073/ pnas. 241442898

Grindley, N. D. (1983). Transposition of Tn3 and related transposons. Cell 32, 3-5. doi: 10.1016/0092-8674(83)90490-7

Guindon, S., and Gascuel, O. (2003). A simple, fast, and accurate algorithm to estimate large phylogenies by maximum likelihood. Syst. Biol. 52, 696-704. doi: 10.1080/10635150390235520

Hagemann, J. B., Pfennigwerth, N., Gatermann, S. G., Von Baum, H., and Essig, A. (2018). KPC-2 carbapenemase-producing Pseudomonas aeruginosa reaching Germany. J. Antimicrob. Chemother. 73, 1812-1814. doi: 10.1093/jac/dky105

Hall, R. M., and Collis, C. M. (1995). Mobile gene cassettes and integrons: capture and spread of genes by site-specific recombination. Mol. Microbiol. 15, 593-600. doi: 10.1111/j.1365-2958.1995.tb02368.x

Han, S., Zaniewski, R. P., Marr, E. S., Lacey, B. M., Tomaras, A. P., Evdokimov, A., et al. (2010). Structural basis for effectiveness of siderophore-conjugated monocarbams against clinically relevant strains of Pseudomonas aeruginosa. Proc. Natl. Acad. Sci. U.S.A. 107, 22002-22007. doi: 10.1073/pnas.1013092107

Hanson, N. D., Hossain, A., Buck, L., Moland, E. S., and Thomson, K. S. (2006). First occurrence of a Pseudomonas aeruginosa isolate in the United States producing an IMP metallo-beta-lactamase, IMP-18. Antimicrob. Agents Chemother. 50, 2272-2273. doi: 10.1128/aac.01440-05

Hishinuma, T., Tada, T., Kuwahara-Arai, K., Yamamoto, N., Shimojima, M., and Kirikae, T. (2018). Spread of GES-5 carbapenemase-producing Pseudomonas aeruginosa clinical isolates in Japan due to clonal expansion of ST235. PLoS One 13:e0207134. doi: 10.1371/journal.pone.0207134

Honda, N. H., Aoki, K., Kamisasanuki, T., Matsuda, N., To, M., Matsushima, H., et al. (2019). Isolation of three distinct carbapenemase-producing Gramnegative bacteria from a Vietnamese medical tourist. J. Infect. Chemother. 25, 811-815. doi: 10.1016/j.jiac.2019.03.020

Hong, J. S., Yoon, E. J., Lee, H., Jeong, S. H., and Lee, K. (2016). Clonal Dissemination of Pseudomonas aeruginosa Sequence Type 235 isolates carrying blaIMP-6 and emergence of blaGES-24 and blaIMP-10 on novel genomic islands PAGI-15 and -16 in South Korea. Antimicrob. Agents Chemother. 60, 7216-7223.

Hrabak, J., Cervena, D., Izdebski, R., Duljasz, W., Gniadkowski, M., Fridrichova, M., et al. (2011). Regional spread of Pseudomonas aeruginosa ST357 producing IMP-7 metallo-beta-lactamase in Central Europe. J. Clin. Microbiol. 49, 474475. doi: $10.1128 / \mathrm{jcm} .00684-10$

Hrabak, J., Fridrichova, M., Stolbova, M., Bergerova, T., Zemlickova, H., and Urbaskova, P. (2009). First identification of metallo-beta-lactamase-producing Pseudomonas aeruginosa in the Czech Republic. Euro Surveill. 14, 19102. 
Hu, Y. Y., Gu, D. X., Cai, J. C., Zhou, H. W., and Zhang, R. (2015). Emergence of KPC-2-producing Pseudomonas aeruginosa sequence type 463 isolates in Hangzhou, China. Antimicrob. Agents Chemother. 59, 2914-2917. doi: 10.1128/ aac.04903-14

Jabalameli, F., Taki, E., Emaneini, M., and Beigverdi, R. (2018). Prevalence of metallo-beta-lactamase-encoding genes among carbapenem-resistant Pseudomonas aeruginosa strains isolated from burn patients in Iran. Rev. Soc. Bras. Med. Trop. 51, 270-276. doi: 10.1590/0037-8682-0044-2018

Jacome, P. R., Alves, L. R., Cabral, A. B., Lopes, A. C., and Maciel, M. A. (2012). First report of KPC-producing Pseudomonas aeruginosa in Brazil. Antimicrob. Agents Chemother. 56, 4990. doi: 10.1128/aac.00699-12

Janvier, F., Jeannot, K., Tesse, S., Robert-Nicoud, M., Delacour, H., Rapp, C., et al. (2013). Molecular characterization of blaNDM-1 in a sequence type 235 Pseudomonas aeruginosa isolate from France. Antimicrob. Agents Chemother. 57, 3408-3411. doi: 10.1128/aac.02334-12

Jeannot, K., Guessennd, N., Fournier, D., Muller, E., Gbonon, V., and Plesiat, P. (2013). Outbreak of metallo-beta-lactamase VIM-2-positive strains of Pseudomonas aeruginosa in the Ivory Coast. J. Antimicrob. Chemother. 68, 2952-2954. doi: 10.1093/jac/dkt296

Jobanputra, R. S., and Datta, N. (1974). Trimethoprim R factors in enterobacteria from clinical specimens. J. Med. Microbiol. 7, 169-177. doi: 10.1099/002226157-2-169

Jovcic, B., Lepsanovic, Z., Begovic, J., Rakonjac, B., Perovanovic, J., Topisirovic, L., et al. (2013). The clinical isolate Pseudomonas aeruginosa MMA83 carries two copies of the blaNDM-1 gene in a novel genetic context. Antimicrob. Agents Chemother. 57, 3405-3407. doi: 10.1128/aac.02312-12

Jovcic, B., Lepsanovic, Z., Suljagic, V., Rackov, G., Begovic, J., Topisirovic, L., et al. (2011). Emergence of NDM-1 metallo-beta-lactamase in Pseudomonas aeruginosa clinical isolates from Serbia. Antimicrob. Agents Chemother. 55, 3929-3931.

Juan, C., Beceiro, A., Gutierrez, O., Alberti, S., Garau, M., Perez, J. L., et al. (2008). Characterization of the new metallo-beta-lactamase VIM-13 and its integron-borne gene from a Pseudomonas aeruginosa clinical isolate in Spain. Antimicrob. Agents Chemother. 52, 3589-3596. doi: 10.1128/aac.00465-08

Karlowsky, J. A., Kazmierczak, K. M., De Jonge, B. L. M., Hackel, M. A., Sahm, D. F., and Bradford, P. A. (2017). In vitro activity of aztreonam-avibactam against Enterobacteriaceae and Pseudomonas aeruginosa isolated by clinical laboratories in 40 countries from 2012 to 2015. Antimicrob. Agents Chemother. 61, e00472-17. doi: 10.1128/AAC.00472-17

Karlowsky, J. A., Lob, S. H., Raddatz, J., Depestel, D. D., Young, K., Motyl, M. R., et al. (2020). In vitro activity of imipenem/relebactam and ceftolozane/tazobactam against clinical isolates of Gram-negative bacilli with difficult-to-treat resistance and multidrug-resistant phenotypes - SMART United States 2015-2017. Clin. Infect. Dis. doi: 10.1093/cid/ciaa381 [Epub ahead of print].

Kateete, D. P., Nakanjako, R., Namugenyi, J., Erume, J., Joloba, M. L., and Najjuka, C. F. (2016). Carbapenem resistant Pseudomonas aeruginosa and Acinetobacter baumannii at Mulago Hospital in Kampala, Uganda (2007-2009). Springerplus 5, 1308 .

Kazmierczak, K. M., Biedenbach, D. J., Hackel, M., Rabine, S., De Jonge, B. L., Bouchillon, S. K., et al. (2016a). Global dissemination of blaKPC into bacterial species beyond Klebsiella pneumoniae and in vitro susceptibility to ceftazidimeavibactam and aztreonam-avibactam. Antimicrob. Agents Chemother. 60, 44904500. doi: 10.1128/aac.00107-16

Kazmierczak, K. M., Rabine, S., Hackel, M., Mclaughlin, R. E., Biedenbach, D. J., Bouchillon, S. K., et al. (2016b). Multiyear, multinational survey of the incidence and global distribution of metallo-beta-lactamase-producing Enterobacteriaceae and Pseudomonas aeruginosa. Antimicrob. Agents Chemother. 60, 1067-1078. doi: 10.1128/aac.02379-15

Khajuria, A., Praharaj, A. K., Kumar, M., and Grover, N. (2013). Emergence of NDM - 1 in the clinical isolates of Pseudomonas aeruginosa in India. J. Clin. Diagn. Res. 7, 1328-1331.

Khosravi, A. D., and Mihani, F. (2008). Detection of metallo-beta-lactamaseproducing Pseudomonas aeruginosa strains isolated from burn patients in Ahwaz, Iran. Diagn. Microbiol. Infect. Dis. 60, 125-128. doi: 10.1016/j. diagmicrobio.2007.08.003

Khosravi, Y., Tee Tay, S., and Vadivelu, J. (2010). Metallo-beta-lactamaseproducing imipenem-resistant Pseudomonas aeruginosa clinical isolates in a university teaching hospital in Malaysia: detection of IMP7 and first identification of IMP-4, VIM-2, and VIM-11. Diagn. Microbiol. Infect. Dis. 67, 294-296. doi: 10.1016/j.diagmicrobio.2010. 02.010

Khuntayaporn, P., Yamprayoonswat, W., Yasawong, M., and Chomnawang, M. T. (2019). Dissemination of carbapenem-resistance among multidrug resistant Pseudomonas aeruginosa carrying metallo-beta-lactamase genes, including the novel blaIMP-65 gene in Thailand. Infect. Chemother. 51, 107-118. doi: 10. 3947/ic.2019.51.2.107

Klockgether, J., Cramer, N., Wiehlmann, L., Davenport, C. F., and Tummler, B. (2011). Pseudomonas aeruginosa genomic structure and diversity. Front. Microbiol. 2:150. doi: 10.3389/fmicb.2011.00150

Klockgether, J., Reva, O., Larbig, K., and Tummler, B. (2004). Sequence analysis of the mobile genome island pKLC102 of Pseudomonas aeruginosa C. J. Bacteriol. 186, 518-534. doi: 10.1128/jb.186.2.518-534.2004

Koh, T. H., Khoo, C. T., Tan, T. T., Arshad, M. A., Ang, L. P., Lau, L. J., et al. (2010). Multilocus sequence types of carbapenem-resistant Pseudomonas aeruginosa in Singapore carrying metallo-beta-lactamase genes, including the novel blaIMP-26 gene. J. Clin. Microbiol. 48, 2563-2564. doi: 10.1128/jcm. 01905-09

Kohler, T., Michea-Hamzehpour, M., Epp, S. F., and Pechere, J. C. (1999). Carbapenem activities against Pseudomonas aeruginosa: respective contributions of OprD and efflux systems. Antimicrob. Agents Chemother. 43, 424-427. doi: 10.1128/aac.43.2.424

Korfhagen, T. R., Ferrel, J. A., Menefee, C. L., and Loper, J. C. (1976). Resistance plasmids of Pseudomonas aeruginosa: change from conjugative to nonconjugative in a hospital population. Antimicrob. Agents Chemother. 9, 810-816. doi: 10.1128/aac.9.5.810

Kouda, S., Kuwahara, R., Ohara, M., Shigeta, M., Fujiwara, T., Komatsuzawa, H., et al. (2007). First isolation of blaIMP-7 in a Pseudomonas aeruginosa in Japan. J. Infect. Chemother. 13, 276-277. doi: 10.1007/s10156-007-0520-0

Kouda, S., Ohara, M., Onodera, M., Fujiue, Y., Sasaki, M., Kohara, T., et al. (2009). Increased prevalence and clonal dissemination of multidrug-resistant Pseudomonas aeruginosa with the blaIMP-1 gene cassette in Hiroshima. J. Antimicrob. Chemother. 64, 46-51. doi: 10.1093/jac/dkp142

Krizova, L., Dijkshoorn, L., and Nemec, A. (2011). Diversity and evolution of AbaR genomic resistance islands in Acinetobacter baumannii strains of European clone I. Antimicrob. Agents Chemother. 55, 3201-3206. doi: 10.1128/aac. 00221-11

Ktari, S., Mnif, B., Znazen, A., Rekik, M., Mezghani, S., Mahjoubi-Rhimi, F., et al. (2011). Diversity of beta-lactamases in Pseudomonas aeruginosa isolates producing metallo-beta-lactamase in two Tunisian hospitals. Microb. Drug Resist. 17, 25-30.

Kulkova, N., Babalova, M., Sokolova, J., and Krcmery, V. (2015). First report of New Delhi metallo-beta-lactamase-1-producing strains in Slovakia. Microb. Drug Resist. 21, 117-120. doi: 10.1089/mdr.2013.0162

Kumarasamy, K. K., Toleman, M. A., Walsh, T. R., Bagaria, J., Butt, F., Balakrishnan, R., et al. (2010). Emergence of a new antibiotic resistance mechanism in India, Pakistan, and the UK: a molecular, biological, and epidemiological study. Lancet Infect. Dis. 10, 597-602. doi: 10.1016/s14733099(10)70143-2

Kung, V. L., Ozer, E. A., and Hauser, A. R. (2010). The accessory genome of Pseudomonas aeruginosa. Microbiol. Mol. Biol. Rev. 74, 621-641. doi: 10.1128/ mmbr.00027-10

Lauretti, L., Riccio, M. L., Mazzariol, A., Cornaglia, G., Amicosante, G., Fontana, R., et al. (1999). Cloning and characterization of blaVIM, a new integron-borne metallo-beta-lactamase gene from a Pseudomonas aeruginosa clinical isolate. Antimicrob. Agents Chemother. 43, 1584-1590. doi: 10.1128/aac.43.7.1584

Li, X. Z., Nikaido, H., and Poole, K. (1995). Role of mexA-mexB-oprM in antibiotic efflux in Pseudomonas aeruginosa. Antimicrob. Agents Chemother. 39, 19481953. doi: 10.1128/aac.39.9.1948

Lister, P. D., Wolter, D. J., and Hanson, N. D. (2009). Antibacterialresistant Pseudomonas aeruginosa: clinical impact and complex regulation of chromosomally encoded resistance mechanisms. Clin. Microbiol. Rev. 22, 582-610. doi: 10.1128/cmr.00040-09

Livermore, D. M. (1992). Interplay of impermeability and chromosomal betalactamase activity in imipenem-resistant Pseudomonas aeruginosa. Antimicrob. Agents Chemother. 36, 2046-2048. doi: 10.1128/aac.36.9.2046 
Livermore, D. M., and Yang, Y. J. (1987). Beta-lactamase lability and inducer power of newer beta-lactam antibiotics in relation to their activity against betalactamase-inducibility mutants of Pseudomonas aeruginosa. J. Infect. Dis. 155, 775-782. doi: 10.1093/infdis/155.4.775

Lob, S. H., Karlowsky, J. A., Young, K., Motyl, M. R., Hawser, S., Kothari, N. D., et al. (2020). In vitro activity of imipenem-relebactam against resistant phenotypes of Enterobacteriaceae and Pseudomonas aeruginosa isolated from intraabdominal and urinary tract infection samples - SMART Surveillance Europe 2015-2017. J. Med. Microbiol. 69, 207-217. doi: 10.1099/jmm.0.001142

Luyt, C. E., Aubry, A., Lu, Q., Micaelo, M., Brechot, N., Brossier, F., et al. (2014). Imipenem, meropenem, or doripenem to treat patients with Pseudomonas aeruginosa ventilator-associated pneumonia. Antimicrob. Agents Chemother. 58, 1372-1380. doi: 10.1128/aac.02109-13

Mac Aogain, M., Rogers, T. R., and Crowley, B. (2016). Identification of emergent blaCMY-2-carrying Proteus mirabilis lineages by whole-genome sequencing. New Microbes New Infect. 9, 58-62. doi: 10.1016/j.nmni.2015.11.012

Malkocoglu, G., Aktas, E., Bayraktar, B., Otlu, B., and Bulut, M. E. (2017). VIM-1, VIM-2, and GES-5 Carbapenemases among Pseudomonas aeruginosa isolates at a tertiary hospital in Istanbul, Turkey. Microb. Drug Resist. 23, 328-334. doi: 10.1089/mdr.2016.0012

Manenzhe, R. I., Zar, H. J., Nicol, M. P., and Kaba, M. (2015). The spread of carbapenemase-producing bacteria in Africa: a systematic review. J. Antimicrob. Chemother. 70, 23-40. doi: 10.1093/jac/dku356

Mano, Y., Saga, T., Ishii, Y., Yoshizumi, A., Bonomo, R. A., Yamaguchi, K., et al. (2015). Molecular analysis of the integrons of metallo-betalactamase-producing Pseudomonas aeruginosa isolates collected by nationwide surveillance programs across Japan. BMC Microbiol. 15:41. doi: 10.1186/ s12866-015-0378-8

Margaret, B. S., Drusano, G. L., and Standiford, H. C. (1989). Emergence of resistance to carbapenem antibiotics in Pseudomonas aeruginosa. J. Antimicrob. Chemother. 24(Suppl. A), 161-167. doi: 10.1093/jac/24.suppl_a.161

Martinez, E., Marquez, C., Ingold, A., Merlino, J., Djordjevic, S. P., Stokes, H. W., et al. (2012). Diverse mobilized class 1 integrons are common in the chromosomes of pathogenic Pseudomonas aeruginosa clinical isolates. Antimicrob. Agents Chemother. 56, 2169-2172. doi: 10.1128/aac.06048-11

Masuda, N., Sakagawa, E., Ohya, S., Gotoh, N., Tsujimoto, H., and Nishino, T. (2000). Substrate specificities of MexAB-OprM, MexCD-OprJ, and MexXYoprM efflux pumps in Pseudomonas aeruginosa. Antimicrob. Agents Chemother. 44, 3322-3327. doi: 10.1128/aac.44.12.3322-3327.2000

Matagne, A., Dubus, A., Galleni, M., and Frere, J. M. (1999). The beta-lactamase cycle: a tale of selective pressure and bacterial ingenuity. Nat. Prod. Rep. 16, 1-19. doi: 10.1039/a705983c

Mataseje, L. F., Peirano, G., Church, D. L., Conly, J., Mulvey, M., and Pitout, J. D. (2016). Colistin-nonsusceptible Pseudomonas aeruginosa sequence type 654 with blaNDM-1 arrives in North America. Antimicrob. Agents Chemother. 60, 1794-1800. doi: 10.1128/aac.02591-15

Maurya, A. P., Choudhury, D., Talukdar, A. D., Dhar Chanda, A., Chakravarty, A., and Bhattacharjee, A. (2014). A report on the presence of GES-5 extended spectrum beta-lactamase producing Pseudomonas aeruginosa associated with urinary tract infection from north-east India. Indian J. Med. Res. 140, 565-567.

Mazzariol, A., Mammina, C., Koncan, R., Di Gaetano, V., Di Carlo, P., Cipolla, D., et al. (2011). A novel VIM-type metallo-beta-lactamase (VIM-14) in a Pseudomonas aeruginosa clinical isolate from a neonatal intensive care unit. Clin. Microbiol. Infect. 17, 722-724. doi: 10.1111/j.1469-0691.2010.03424.x

McCarthy, K. L., Jennison, A., Wailan, A. M., and Paterson, D. L. (2017). Draft Genome Sequence of an IMP-7-Producing Pseudomonas aeruginosa bloodstream infection isolate from Australia. Genome Announc. 5, e00596-17. doi: 10.1128/genomeA.00596-17

McCracken, M. G., Adam, H. J., Blondeau, J. M., Walkty, A. J., Karlowsky, J. A., Hoban, D. J., et al. (2019). Characterization of carbapenem-resistant and XDR Pseudomonas aeruginosa in Canada: results of the CANWARD 2007-16 study. J. Antimicrob. Chemother. 74, iv32-iv38.

Mikucionyte, G., Zamorano, L., Vitkauskiene, A., Lopez-Causape, C., Juan, C., Mulet, X., et al. (2016). Nosocomial dissemination of VIM-2-producing ST235 Pseudomonas aeruginosa in Lithuania. Eur. J. Clin. Microbiol. Infect. Dis. 35, 195-200. doi: 10.1007/s10096-015-2529-0

Minakhina, S., Kholodii, G., Mindlin, S., Yurieva, O., and Nikiforov, V. (1999). Tn5053 family transposons are res site hunters sensing plasmidal res sites occupied by cognate resolvases. Mol. Microbiol. 33, 1059-1068. doi: 10.1046/ j.1365-2958.1999.01548.x

Minami, S., Akama, M., Araki, H., Watanabe, Y., Narita, H., Iyobe, S., et al. (1996). Imipenem and cephem resistant Pseudomonas aeruginosa carrying plasmids coding for class B beta-lactamase. J. Antimicrob. Chemother. 37, 433-444. doi: $10.1093 / \mathrm{jac} / 37.3 .433$

Moradali, M. F., Ghods, S., and Rehm, B. H. (2017). Pseudomonas aeruginosa lifestyle: a paradigm for adaptation, Survival, and Persistence. Front. Cell Infect. Microbiol. 7:39. doi: 10.3389/fcimb.2017.00039

Moran-Barrio, J., Lisa, M. N., Larrieux, N., Drusin, S. I., Viale, A. M., Moreno, D. M., et al. (2016). Crystal structure of the metallo-beta-lactamase gob in the periplasmic dizinc form reveals an unusual metal site. Antimicrob. Agents Chemother. 60, 6013-6022. doi: 10.1128/aac.01067-16

Mosquera-Rendon, J., Rada-Bravo, A. M., Cardenas-Brito, S., Corredor, M., Restrepo-Pineda, E., and Benitez-Paez, A. (2016). Pangenome-wide and molecular evolution analyses of the Pseudomonas aeruginosa species. BMC Genomics 17:45. doi: 10.1186/s12864-016-2364-4

Moura, A., Soares, M., Pereira, C., Leitao, N., Henriques, I., and Correia, A. (2009). INTEGRALL: a database and search engine for integrons, integrases and gene cassettes. Bioinformatics 25, 1096-1098. doi: 10.1093/bioinformatics/btp105

Moyo, S., Haldorsen, B., Aboud, S., Blomberg, B., Maselle, S. Y., Sundsfjord, A., et al. (2015). Identification of VIM-2-producing Pseudomonas aeruginosa from Tanzania is associated with sequence types 244 and 640 and the location of blaVIM-2 in a TniC integron. Antimicrob. Agents Chemother. 59, 682-685. doi: 10.1128/aac.01436-13

Naas, T., Bonnin, R. A., Cuzon, G., Villegas, M. V., and Nordmann, P. (2013). Complete sequence of two KPC-harbouring plasmids from Pseudomonas aeruginosa. J. Antimicrob. Chemother. 68, 1757-1762. doi: 10.1093/jac/dkt094

Naas, T., Cuzon, G., Truong, H. V., and Nordmann, P. (2012). Role of ISKpn7 and deletions in blaKPC gene expression. Antimicrob. Agents Chemother. 56, 4753-4759.

NCBI (2020). Genome. Bethesda, MA: National Center for Biotechnology Information.

Nho, S. O., Jin, J. S., Kim, J. W., Oh, J. Y., Kim, J., Lee, Y. C., et al. (2008). Dissemination of the blaIMP-1 and blaVIM-2 metallo-beta-lactamase genes among genetically unrelated Pseudomonas aeruginosa isolates in a South Korean hospital. Int. J. Antimicrob. Agents 31, 586-588. doi: 10.1016/ j.ijantimicag.2008.02.005

Pacheco, T., Bustos-Cruz, R. H., Abril, D., Arias, S., Uribe, L., Rincon, J., et al. (2019). Pseudomonas aeruginosa Coharboring blaKPC-2 and blaVIM-2 carbapenemase genes. Antibiotics (Basel) 8, 98. doi: 10.3390/antibiotics8030098

Papagiannitsis, C. C., Medvecky, M., Chudejova, K., Skalova, A., Rotova, V., Spanelova, P., et al. (2017). Molecular characterization of carbapenemaseproducing Pseudomonas aeruginosa of Czech origin and evidence for clonal spread of extensively resistant sequence type 357 expressing IMP-7 metallobeta-lactamase. Antimicrob. Agents Chemother. 61, e01811-17. doi: 10.1128/ AAC.01811-17

Papp-Wallace, K. M., Endimiani, A., Taracila, M. A., and Bonomo, R. A. (2011). Carbapenems: past, present, and future. Antimicrob. Agents Chemother. 55, 4943-4960.

Pasteran, F., Faccone, D., Petroni, A., Rapoport, M., Galas, M., Vazquez, M., et al. (2005). Novel variant (blaVIM-11) of the metallo-beta-lactamase blaVIM family in a GES-1 extended-spectrum-beta-lactamase-producing Pseudomonas aeruginosa clinical isolate in Argentina. Antimicrob. Agents Chemother. 49, 474-475. doi: 10.1128/aac.49.1.474-475.2005

Paton, R., Miles, R. S., Hood, J., Amyes, S. G., Miles, R. S., and Amyes, S. G. (1993). ARI 1: Beta-lactamase-mediated imipenem resistance in Acinetobacter baumannii. Int. J. Antimicrob. Agents 2, 81-87. doi: 10.1016/0924-8579(93) 90045-7

Paul, D., Dhar Chanda, D., Maurya, A. P., Mishra, S., Chakravarty, A., Sharma, G. D., et al. (2015). Co-carriage of blaKPC-2 and blaNDM-1 in clinical isolates of Pseudomonas aeruginosa associated with hospital infections from India. PLoS One 10:e0145823. doi: 10.1371/journal.pone.0145823

Pfennigwerth, N., Lange, F., Belmar Campos, C., Hentschke, M., Gatermann, S. G., and Kaase, M. (2017). Genetic and biochemical characterization of HMB-1, a novel subclass B1 metallo-beta-lactamase found in a Pseudomonas aeruginosa clinical isolate. J. Antimicrob. Chemother. 72, 1068-1073. 
Pfizer (2020). Antimicrobial Testing Leadership and Surveillance. Available at: https://atlas-surveillance.com/ (accessed May, 2020).

Pitout, J. D., Chow, B. L., Gregson, D. B., Laupland, K. B., Elsayed, S., and Church, D. L. (2007). Molecular epidemiology of metallo-beta-lactamase-producing Pseudomonas aeruginosa in the Calgary Health Region: emergence of VIM2-producing isolates. J. Clin. Microbiol. 45, 294-298. doi: 10.1128/jcm.0169406

Pitout, J. D., Revathi, G., Chow, B. L., Kabera, B., Kariuki, S., Nordmann, P., et al. (2008). Metallo-beta-lactamase-producing Pseudomonas aeruginosa isolated from a large tertiary centre in Kenya. Clin. Microbiol. Infect. 14, 755-759. doi: 10.1111/j.1469-0691.2008.02030.x

Poirel, L., Naas, T., Nicolas, D., Collet, L., Bellais, S., Cavallo, J. D., et al. (2000). Characterization of VIM-2, a carbapenem-hydrolyzing metallo-beta-lactamase and its plasmid- and integron-borne gene from a Pseudomonas aeruginosa clinical isolate in France. Antimicrob. Agents Chemother. 44, 891-897. doi: 10.1128/aac.44.4.891-897.2000

Poirel, L., Nordmann, P., Lagrutta, E., Cleary, T., and Munoz-Price, L. S. (2010). Emergence of KPC-producing Pseudomonas aeruginosa in the United States. Antimicrob. Agents Chemother. 54, 3072. doi: 10.1128/aac.00513-10

Poirel, L., Weldhagen, G. F., Naas, T., De Champs, C., Dove, M. G., and Nordmann, P. (2001). GES-2, a class A beta-lactamase from Pseudomonas aeruginosa with increased hydrolysis of imipenem. Antimicrob. Agents Chemother. 45, 2598-2603. doi: 10.1128/aac.45.9.2598-2603.2001

Pollini, S., Maradei, S., Pecile, P., Olivo, G., Luzzaro, F., Docquier, J. D., et al. (2013). FIM-1, a new acquired metallo-beta-lactamase from a Pseudomonas aeruginosa clinical isolate from Italy. Antimicrob. Agents Chemother. 57, 410-416. doi: 10.1128/aac.01953-12

Polotto, M., Casella, T., De Lucca Oliveira, M. G., Rubio, F. G., Nogueira, M. L., De Almeida, M. T., et al. (2012). Detection of P. aeruginosa harboring blaCTXM-2, blaGES-1 and blaGES-5, blaIMP-1 and blaSPM-1 causing infections in Brazilian tertiary-care hospital. BMC Infect. Dis. 12:176. doi: 10.1186/14712334-12-176

Pournaras, S., Tsakris, A., Maniati, M., Tzouvelekis, L. S., and Maniatis, A. N. (2002). Novel variant (blaVIM-4) of the metallo-beta-lactamase gene blaVIM-1 in a clinical strain of Pseudomonas aeruginosa. Antimicrob. Agents Chemother. 46, 4026-4028. doi: 10.1128/aac.46.12.4026-4028.2002

Quale, J., Bratu, S., Gupta, J., and Landman, D. (2006). Interplay of efflux system, ampC, and oprD expression in carbapenem resistance of Pseudomonas aeruginosa clinical isolates. Antimicrob. Agents Chemother. 50, 1633-1641. doi: 10.1128/aac.50.5.1633-1641.2006

Queenan, A. M., and Bush, K. (2007). Carbapenemases: the versatile betalactamases. Clin. Microbiol. Rev. 20, 440-458. doi: 10.1128/cmr.00001-07

Radstrom, P., Skold, O., Swedberg, G., Flensburg, J., Roy, P. H., and Sundstrom, L. (1994). Transposon Tn5090 of plasmid R751, which carries an integron, is related to $\mathrm{Tn} 7, \mathrm{Mu}$, and the retroelements. J. Bacteriol. 176, 3257-3268. doi: 10.1128/jb.176.11.3257-3268.1994

Ramirez, D. G., Nicola, F., Zarate, S., Relloso, S., Smayevsky, J., and Arduino, S. (2013). Emergence of Pseudomonas aeruginosa with KPC-type carbapenemase in a teaching hospital: an 8-year study. J. Med. Microbiol. 62, 1565-1570.

Rice, L. B. (2008). Federal funding for the study of antimicrobial resistance in nosocomial pathogens: no ESKAPE. J. Infect. Dis. 197, 1079-1081. doi: 10.1086/ 533452

Rios, P., Rocha, C., Castro, W., Vidal, M., Canal, E., Bernal, M., et al. (2018). Extensively drug-resistant (XDR) Pseudomonas aeruginosa identified in Lima, Peru co-expressing a VIM-2 metallo-beta-lactamase, OXA-1 beta-lactamase and GES-1 extended-spectrum beta-lactamase. JMM Case Rep. 5, e005154.

Roberts, A. P., Chandler, M., Courvalin, P., Guedon, G., Mullany, P., Pembroke, T., et al. (2008). Revised nomenclature for transposable genetic elements. Plasmid $60,167-173$

Robledo, I. E., Aquino, E. E., and Vazquez, G. J. (2011). Detection of the KPC gene in Escherichia coli, Klebsiella pneumoniae, Pseudomonas aeruginosa, and Acinetobacter baumannii during a PCR-based nosocomial surveillance study in Puerto Rico. Antimicrob. Agents Chemother. 55, 2968-2970. doi: 10.1128/aac. 01633-10

Rodriguez-Martinez, J. M., Poirel, L., and Nordmann, P. (2009a). Extendedspectrum cephalosporinases in Pseudomonas aeruginosa. Antimicrob. Agents Chemother. 53, 1766-1771. doi: 10.1128/aac.01410-08
Rodriguez-Martinez, J. M., Poirel, L., and Nordmann, P. (2009b). Molecular epidemiology and mechanisms of carbapenem resistance in Pseudomonas aeruginosa. Antimicrob. Agents Chemother. 53, 4783-4788. doi: 10.1128/aac. 00574-09

Rowe-Magnus, D. A., Guerout, A. M., and Mazel, D. (2002). Bacterial resistance evolution by recruitment of super-integron gene cassettes. Mol. Microbiol. 43, 1657-1669. doi: 10.1046/j.1365-2958.2002.02861.x

Roy Chowdhury, P., Scott, M., Worden, P., Huntington, P., Hudson, B., Karagiannis, T., et al. (2016). Genomic islands 1 and 2 play key roles in the evolution of extensively drug-resistant ST235 isolates of Pseudomonas aeruginosa. Open Biol. 6, 150175. doi: 10.1098/rsob.150175

Roy Chowdhury, P., Scott, M. J., and Djordjevic, S. P. (2017). Genomic islands 1 and 2 carry multiple antibiotic resistance genes in Pseudomonas aeruginosa ST235, ST253, ST111 and ST175 and are globally dispersed. J. Antimicrob. Chemother. 72, 620-622. doi: 10.1093/jac/dkw471

Ryoo, N. H., Lee, K., Lim, J. B., Lee, Y. H., Bae, I. K., and Jeong, S. H. (2009). Outbreak by meropenem-resistant Pseudomonas aeruginosa producing IMP-6 metallo-beta-lactamase in a Korean hospital. Diagn. Microbiol. Infect. Dis. 63, 115-117. doi: 10.1016/j.diagmicrobio.2008.08.019

Salabi, A. E., Toleman, M. A., Weeks, J., Bruderer, T., Frei, R., and Walsh, T. R. (2010). First report of the metallo-beta-lactamase SPM-1 in Europe. Antimicrob. Agents Chemother. 54, 582.

Samuelsen, O., Toleman, M. A., Sundsfjord, A., Rydberg, J., Leegaard, T. M., Walder, M., et al. (2010). Molecular epidemiology of metallo-beta-lactamaseproducing Pseudomonas aeruginosa isolates from Norway and Sweden shows import of international clones and local clonal expansion. Antimicrob. Agents Chemother. 54, 346-352. doi: 10.1128/aac.00824-09

Sato, H., Frank, D. W., Hillard, C. J., Feix, J. B., Pankhaniya, R. R., Moriyama, K., et al. (2003). The mechanism of action of the Pseudomonas aeruginosa-encoded type III cytotoxin, ExoU. EMBO J. 22, 2959-2969. doi: 10.1093/emboj/cdg290

Schneider, I., Keuleyan, E., Rasshofer, R., Markovska, R., Queenan, A. M., and Bauernfeind, A. (2008). VIM-15 and VIM-16, two new VIM-2-like metallo-beta-lactamases in Pseudomonas aeruginosa isolates from Bulgaria and Germany. Antimicrob. Agents Chemother. 52, 2977-2979. doi: 10.1128/aac. 00175-08

Schweizer, C., Bischoff, P., Bender, J., Kola, A., Gastmeier, P., Hummel, M., et al. (2019). Plasmid-mediated transmission of KPC-2 Carbapenemase in Enterobacteriaceae in critically ill patients. Front. Microbiol. 10:276. doi: 10. $3389 /$ fmicb.2019.00276

Senda, K., Arakawa, Y., Ichiyama, S., Nakashima, K., Ito, H., Ohsuka, S., et al. (1996a). PCR detection of metallo-beta-lactamase gene (blaIMP) in Gramnegative rods resistant to broad-spectrum beta-lactams. J. Clin. Microbiol. 34, 2909-2913. doi: 10.1128/jcm.34.12.2909-2913.1996

Senda, K., Arakawa, Y., Nakashima, K., Ito, H., Ichiyama, S., Shimokata, K., et al. (1996b). Multifocal outbreaks of metallo-beta-lactamase-producing Pseudomonas aeruginosa resistant to broad-spectrum beta-lactams, including carbapenems. Antimicrob. Agents Chemother. 40, 349-353. doi: 10.1128/aac. 40.2.349

Sevillano, E., Gallego, L., and Garcia-Lobo, J. M. (2009). First detection of the OXA40 carbapenemase in P. aeruginosa isolates, located on a plasmid also found in A. baumannii. Pathol. Biol. (Paris) 57, 493-495. doi: 10.1016/j.patbio.2008.05. 002

Shapiro, J. A., and Sporn, P. (1977). Tn402: a new transposable element determining trimethoprim resistance that inserts in bacteriophage lambda. J. Bacteriol. 129, 1632-1635. doi: 10.1128/jb.129.3.1632-1635.1977

Shen, K., Sayeed, S., Antalis, P., Gladitz, J., Ahmed, A., Dice, B., et al. (2006). Extensive genomic plasticity in Pseudomonas aeruginosa revealed by identification and distribution studies of novel genes among clinical isolates. Infect. Immun. 74, 5272-5283. doi: 10.1128/iai.00546-06

Sherry, N. L., Baines, S. L., and Howden, B. P. (2018). Ceftazidime/avibactam susceptibility by three different susceptibility testing methods in carbapenemase-producing Gram-negative bacteria from Australia. Int. J. Antimicrob. Agents 52, 82-85. doi: 10.1016/j.ijantimicag.2018.02.017

Shi, L., Liang, Q., Feng, J., Zhan, Z., Zhao, Y., Yang, W., et al. (2018). Coexistence

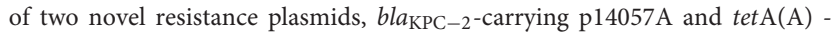
carrying p14057B, in Pseudomonas aeruginosa. Virulence 9, 306-311. doi: 10. $1080 / 21505594.2017 .1372082$ 
Siarkou, V. I., Vitti, D., Protonotariou, E., Ikonomidis, A., and Sofianou, D. (2009). Molecular epidemiology of outbreak-related Pseudomonas aeruginosa strains carrying the novel variant blaVIM-17 metallo-beta-lactamase gene. Antimicrob. Agents Chemother. 53, 1325-1330. doi: 10.1128/aac.01230-08

Silveira, M., Albano, R., Asensi, M., and Assef, A. P. (2014). The draft genome sequence of multidrug-resistant Pseudomonas aeruginosa strain CCBH4851, a nosocomial isolate belonging to clone SP (ST277) that is prevalent in Brazil. Mem. Inst. Oswaldo Cruz 109, 1086-1087. doi: 10.1590/0074-0276140336

Slack, M. P. (1981). Antipseudomonal beta-lactams. J. Antimicrob. Chemother. 8, 165-170. doi: 10.1093/jac/8.3.165

Sole, M., Pitart, C., Roca, I., Fabrega, A., Salvador, P., Munoz, L., et al. (2011). First description of an Escherichia coli strain producing NDM-1 carbapenemase in Spain. Antimicrob. Agents Chemother. 55, 4402-4404. doi: 10.1128/aac.006 42-11

Stoesser, N., Sheppard, A. E., Peirano, G., Anson, L. W., Pankhurst, L., Sebra, R., et al. (2017). Genomic epidemiology of global Klebsiella pneumoniae carbapenemase (KPC)-producing Escherichia coli. Sci. Rep. 7, 5917.

Sun, F., Zhou, D., Wang, Q., Feng, J., Feng, W., Luo, W., et al. (2016). The first report of detecting the blaSIM-2 gene and determining the complete sequence of the SIM-encoding plasmid. Clin. Microbiol. Infect. 22, 347-351. doi: 10.1016/ j.cmi.2015.12.001

Tada, T., Hishinuma, T., Watanabe, S., Uchida, H., Tohya, M., Kuwahara-Arai, K., et al. (2019). Molecular characterization of multidrug-resistant Pseudomonas aeruginosa isolates in hospitals in Myanmar. Antimicrob. Agents Chemother. 63, e02397-18. doi: 10.1128/AAC.02397-18

Tada, T., Shimada, K., Satou, K., Hirano, T., Pokhrel, B. M., Sherchand, J. B., et al. (2017). Pseudomonas aeruginosa clinical isolates in nepal coproducing metallo-beta-lactamases and 16S rRNA methyltransferases. Antimicrob. Agents Chemother. 61, e00694-17. doi: 10.1128/AAC.00694-17

Tai, A. S., Kidd, T. J., Whiley, D. M., Ramsay, K. A., Buckley, C., Bell, S. C., et al. (2015). Molecular surveillance for carbapenemase genes in carbapenemresistant Pseudomonas aeruginosa in Australian patients with cystic fibrosis. Pathology 47, 156-160. doi: 10.1097/pat.0000000000000216

Tansirichaiya, S., Rahman, M. A., and Roberts, A. P. (2019). The transposon registry. Mob. DNA 10, 40.

Tohya, M., Tada, T., Watanabe, S., Kuwahara-Arai, K., Zin, K. N., Zaw, N. N., et al. (2019). Emergence of carbapenem-resistant Pseudomonas asiatica producing NDM-1 and VIM-2 metallo-beta-lactamases in Myanmar. Antimicrob. Agents Chemother. 63, e00475-19. doi: 10.1128/AAC.00475-19

Toleman, M. A., Bennett, P. M., and Walsh, T. R. (2006). ISCR elements: novel gene-capturing systems of the 21st century? Microbiol. Mol. Biol. Rev. 70, 296-316. doi: 10.1128/mmbr.00048-05

Toleman, M. A., Rolston, K., Jones, R. N., and Walsh, T. R. (2004). blaVIM7, an evolutionarily distinct metallo-beta-lactamase gene in a Pseudomonas aeruginosa isolate from the United States. Antimicrob. Agents Chemother. 48, 329-332. doi: 10.1128/aac.48.1.329-332.2004

Toleman, M. A., Simm, A. M., Murphy, T. A., Gales, A. C., Biedenbach, D. J., Jones, R. N., et al. (2002). Molecular characterization of SPM-1, a novel metallo-betalactamase isolated in Latin America: report from the SENTRY antimicrobial surveillance programme. J. Antimicrob. Chemother. 50, 673-679. doi: 10.1093/ $\mathrm{jac} / \mathrm{dkf} 210$

Treepong, P., Kos, V. N., Guyeux, C., Blanc, D. S., Bertrand, X., Valot, B., et al. (2018). Global emergence of the widespread Pseudomonas aeruginosa ST235 clone. Clin. Microbiol. Infect. 24, 258-266. doi: 10.1016/j.cmi.2017.06.018

Urbanowicz, P., Izdebski, R., Baraniak, A., Zabicka, D., Ziolkowski, G., Hryniewicz, W., et al. (2019). Pseudomonas aeruginosa with NDM-1, DIM-1 and PME-1 beta-lactamases, and RmtD3 16S rRNA methylase, encoded by new genomic islands. J. Antimicrob. Chemother. 74, 3117-3119. doi: 10.1093/jac/dkz262

Viedma, E., Juan, C., Acosta, J., Zamorano, L., Otero, J. R., Sanz, F., et al. (2009). Nosocomial spread of colistin-only-sensitive sequence type 235 Pseudomonas aeruginosa isolates producing the extended-spectrum beta-lactamases GES-1 and GES-5 in Spain. Antimicrob. Agents Chemother. 53, 4930-4933. doi: 10. 1128/aac.00900-09

Viedma, E., Juan, C., Villa, J., Barrado, L., Orellana, M. A., Sanz, F., et al. (2012). VIM-2-producing multidrug-resistant Pseudomonas aeruginosa ST175 clone, Spain. Emerg. Infect. Dis. 18, 1235-1241.

Villegas, M. V., Lolans, K., Correa, A., Kattan, J. N., Lopez, J. A., Quinn, J. P., et al. (2007). First identification of Pseudomonas aeruginosa isolates producing a KPC-type carbapenem-hydrolyzing beta-lactamase. Antimicrob. Agents Chemother. 51, 1553-1555. doi: 10.1128/aac.01405-06

Walkty, A., Alexander, D. C., Karlowsky, J. A., Nichol, K., and Embil, J. (2019). Report of a KPC-producing Pseudomonas aeruginosa isolate in Canada. J. Antimicrob. Chemother. 74, 1748-1749. doi: 10.1093/jac/dkz064

Walters, M. S., Grass, J. E., Bulens, S. N., Hancock, E. B., Phipps, E. C., Muleta, D., et al. (2019). Carbapenem-resistant Pseudomonas aeruginosa at US emerging infections program sites, 2015. Emerg. Infect. Dis. 25, 1281-1288.

Wang, C., Cai, P., Chang, D., and Mi, Z. (2006a). A Pseudomonas aeruginosa isolate producing the GES-5 extended-spectrum beta-lactamase. J. Antimicrob. Chemother. 57, 1261-1262. doi: 10.1093/jac/dkl116

Wang, C., Wang, J., and Mi, Z. (2006b). Pseudomonas aeruginosa producing VIM-2 metallo-beta-lactamases and carrying two aminoglycoside-modifying enzymes in China. J. Hosp. Infect. 62, 522-524. doi: 10.1016/j.jhin.2005. 10.002

Watanabe, M., Iyobe, S., Inoue, M., and Mitsuhashi, S. (1991). Transferable imipenem resistance in Pseudomonas aeruginosa. Antimicrob. Agents Chemother. 35, 147-151. doi: 10.1128/aac.35.1.147

Wendel, A. F., Kolbe-Busch, S., Ressina, S., Schulze-Robbecke, R., Kindgen-Milles, D., Lorenz, C., et al. (2015). Detection and termination of an extended lowfrequency hospital outbreak of GIM-1-producing Pseudomonas aeruginosa ST111 in Germany. Am. J. Infect. Control 43, 635-639. doi: 10.1016/j.ajic.2015. 02.024

Xiong, J., Hynes, M. F., Ye, H., Chen, H., Yang, Y., M'zali, F., et al. (2006). blaIMP9 and its association with large plasmids carried by Pseudomonas aeruginosa isolates from the People's Republic of China. Antimicrob. Agents Chemother. 50, 355-358. doi: 10.1128/aac.50.1.355-358.2006

Yaghi, J., Fattouh, N., Akkawi, C., Chamy, L. E., Maroun, R. G., and Khalil, G. (2019). Unusually high prevalence of cosecretion of Ambler Class A and B carbapenemases and nonenzymatic mechanisms in multidrug-resistant clinical isolates of Pseudomonas aeruginosa in Lebanon. Microb. Drug Resist. 26, 150159. doi: $10.1089 / \mathrm{mdr} .2019 .0040$

Yano, H., Kuga, A., Okamoto, R., Kitasato, H., Kobayashi, T., and Inoue, M. (2001). Plasmid-encoded metallo-beta-lactamase (IMP-6) conferring resistance to carbapenems, especially meropenem. Antimicrob. Agents Chemother. 45, 1343-1348. doi: 10.1128/aac.45.5.1343-1348.2001

Yigit, H., Queenan, A. M., Anderson, G. J., Domenech-Sanchez, A., Biddle, J. W., Steward, C. D., et al. (2001). Novel carbapenem-hydrolyzing betalactamase, KPC-1, from a carbapenem-resistant strain of Klebsiella pneumoniae. Antimicrob. Agents Chemother. 45, 1151-1161. doi: 10.1128/aac.45.4.11511161.2001

Yong, D., Toleman, M. A., Bell, J., Ritchie, B., Pratt, R., Ryley, H., et al. (2012). Genetic and biochemical characterization of an acquired subgroup B3 metallobeta-lactamase gene, blaAIM-1, and its unique genetic context in Pseudomonas aeruginosa from Australia. Antimicrob. Agents Chemother. 56, 6154-6159.

Yong, D., Toleman, M. A., Giske, C. G., Cho, H. S., Sundman, K., Lee, K., et al. (2009). Characterization of a new metallo-beta-lactamase gene, blaNDM-1, and a novel erythromycin esterase gene carried on a unique genetic structure in Klebsiella pneumoniae sequence type 14 from India. Antimicrob. Agents Chemother. 53, 5046-5054. doi: 10.1128/aac.00774-09

Yoon, E. J., Kim, D., Lee, H., Lee, H. S., Shin, J. H., Park, Y. S., et al. (2019). Mortality dynamics of Pseudomonas aeruginosa bloodstream infections and the influence of defective OprD on mortality: prospective observational study. J. Antimicrob. Chemother. 74, 2774-2783. doi: 10.1093/jac/dkz245

Yoon, E. J., Kim, J. O., Kim, D., Lee, H., Yang, J. W., Lee, K. J., et al. (2018). Klebsiella pneumoniae carbapenemase producers in South Korea between 2013 and 2015. Front. Microbiol. 9:56. doi: 10.3389/fmicb.2018.00056

Conflict of Interest: The authors declare that the research was conducted in the absence of any commercial or financial relationships that could be construed as a potential conflict of interest.

Copyright $\odot 2021$ Yoon and Jeong. This is an open-access article distributed under the terms of the Creative Commons Attribution License (CC BY). The use, distribution or reproduction in other forums is permitted, provided the original author(s) and the copyright owner(s) are credited and that the original publication in this journal is cited, in accordance with accepted academic practice. No use, distribution or reproduction is permitted which does not comply with these terms. 